STEPHEN MORRIS

Princeton University

HYUN SONG SHIN

London School of Economics

\title{
Central Bank Transparency and the Signal Value of Prices
}

A CENTRAL BANK must be accountable for its actions, and its decisionmaking procedures should meet the highest standards of probity and technical competence. In light of the considerable discretion enjoyed by independent central banks, the standards of accountability that they must meet are perhaps even higher than for most other public institutions. Transparency allows for democratic scrutiny of the central bank and hence is an important precondition for central bank accountability. Few would question the proposition that central banks must be transparent in this broad sense.

A narrower debate over central bank transparency considers whether a central bank should publish its forecasts and whether it should have a publicly announced, numerical target for inflation. This narrower notion of transparency also impinges on issues of accountability and legitimacy, but the main focus in this debate has been on the effectiveness of monetary policy.

Proponents of transparency in this narrower sense point to the importance of the management of expectations in conducting monetary policy. A central bank generally controls directly only the overnight interest rate, "an interest rate that is relevant to virtually no economically interesting transactions," as Alan Blinder has put it. ${ }^{1}$ The links from this direct lever of monetary policy to the prices that matter, such as long-term interest

We thank Benjamin Friedman and Christopher Sims for their comments and guidance. We also thank Marios Angeletos, Alan Blinder, Christian Hellwig, Anil Kashyap, Don Kohn, Chris Kent, Phil Lowe, Ellen Meade, Lars Svensson, and T. N. Srinivasan for comments at various stages of the project.

1. Blinder (1998, p. 70). 
rates, depend almost entirely upon market expectations, and monetary policy is effective only to the extent that the central bank can shape the beliefs of market participants. Long-term interest rates are influenced in large part by the market's expectation of the future course of short-term rates. By charting a path for future short-term rates and communicating this path clearly to the market, the central bank can influence market expectations, thereby affecting mortgage rates, corporate lending rates, and other prices that have a direct impact on the economy. Having thus gained a lever of control over long-term rates, monetary policy achieves its effects through the IS curve, through quantities such as consumption and investment.

Indeed, it would not be an exaggeration to say that many leading monetary economists today see the management of expectations as the task of monetary policy. For Lars Svensson, "monetary policy is to a large extent the management of expectations"; Michael Woodford puts it similarly: "not only do expectations about policy matter, but, at least under current conditions, very little else matters." 2

The reasons for this preeminent role of expectations in monetary policy are explained particularly well for a general audience in a policy speech by Ben Bernanke, titled "The Logic of Monetary Policy."” Bernanke considers whether monetary policy's steering of the economy is in some way analogous to driving a car. Monetary policy actions are akin to stepping on the accelerator or the brake, to stimulate or cool the economy as appropriate given its current state. Bernanke notes that, although this analogy is superficially attractive, it breaks down when one notes the importance of market expectations of the central bank's future actions. If the economy is like a car, then it is a car whose speed at a particular moment depends not on the pressure on the accelerator at that moment, but rather on the expected average pressure on the accelerator over the rest of the trip. Woodford employs a similar transport metaphor: "central banking is not like steering an oil tanker, or even guiding a spacecraft, which follows a trajectory that depends on constantly changing factors, but that does not depend on the vehicle's own expectations about where it is heading." Instead, optimal policy is history dependent, in that the central bank commits itself to a rule that takes into account past conditions, including even some that no longer matter for an evaluation of what is possible to achieve from now

2. Svensson (2004, p. 1); Woodford (2005, p. 3).

3. Bernanke (2004b). 
on. This is so because it was the anticipation of such a rule that determined the market's expectations today. ${ }^{4}$

The pivotal role of market expectations puts the central bank's communication policy at center stage, and this view has been adopted to some extent by all central banks, but embraced most enthusiastically by those that have adopted explicit inflation-targeting monetary regimes. ${ }^{5}$ However, one issue seems to have received less attention than it deserves, namely, the consequences of central bank transparency for the informativeness of prices. In order for the central bank to know how it should manage expectations, it must obtain its cues from signals emanating from the economy, which themselves are the product of market expectations. On the face of it, there is an apparent tension between managing market expectations and learning from market expectations: the central bank cannot manipulate prices and, at the same time, hope that prices yield informative signals. A recent speech by Federal Reserve governor Don Kohn identifies limits to transparency for these reasons. ${ }^{6}$

This tension between managing expectations and learning from them reflects the dual role of a central bank in the conduct of monetary policy. In addition to being an active shaper of events, the central bank must act as a vigilant observer of events, in order to obtain its cues for future actions. The roles are complementary, since only by being a vigilant observer of events can it be effective as an active shaper of outcomes. On the surface at least, there is a worry that an emphasis on the latter role will detract from the former. The central bank holds a mirror up to the economy for cues for its future actions, but the more effective it has been in manipulating the beliefs of the market, the more the central bank will see merely its own reflection.

The dilemma between managing market prices and learning from market prices would disappear if the central bank were omniscient, not having to rely on the information flowing from market prices. Then its only task would be to convey its knowledge to the rest of the economy, thereby aligning market expectations to its own (correct) view. Even if the central

4. Woodford (2005, p. 2); see also Blinder (1998); Woodford (2003b, chapter 7); Svensson and Woodford (2005).

5. See Kuttner (2004) for an overview of the various ways in which inflation targeting has been implemented. Early contributions include Leiderman and Svensson (1995), Bernanke and Mishkin (1997), and Bernanke and others (2001).

6. Kohn (2005). 
bank is far from omniscient, one could argue that it is so much better informed than any other individual agent in the economy that it should convey what it knows forcefully, so as to educate the myriad other actors in the economy. In this view the tension between managing market expectations and learning from market expectations would be resolved in favor of the former.

This way of resolving the tension is implicit in the following argument in another speech by Bernanke, titled "Central Bank Talk and Monetary Policy":

... when the monetary policy committee regularly provides information about its objectives, economic outlook, and policy plans, two benefits result. First, with more complete information available, markets will price financial assets more efficiently. Second, the policymakers will usually find that they have achieved a closer alignment between market participants' expectations about the course of future short-term rates and their own views. ${ }^{7}$

Here Bernanke makes two claims:

-When the central bank conveys its own views clearly, market prices will be more informationally efficient.

-When the central bank conveys its own views clearly, the market's expectations will be closer to the central bank's own expectations.

We will argue that there are strong reasons for believing that the second assertion holds true, but that the first assertion is more open to question. In particular, the stronger are the reasons for believing the second assertion, the more doubtful is the first. In short, the first assertion may be false because the second assertion is true.

\section{Informational Efficiency}

Informational efficiency can be expected to have large favorable welfare consequences via two broad channels: the allocational role of financial market prices in guiding investment decisions, and the information revealed by market outcomes as a guide to the central bank's optimal control problem. We take each of these in turn.

Financial market prices have a large impact on the level and type of investments undertaken. For central bankers, the allocational role of the

7. Bernanke (2004a). 
yield curve in determining the duration of investment projects is of particular importance. Irving Fisher in his Theory of Interest gives the example of three possible uses for a plot of land: for forestry, farming, or strip mining. ${ }^{8}$ The interest rate used to discount future cash flows largely determines the ranking of the three projects. Long-duration projects such as forestry, where the bulk of the payoffs arrive in the distant future, are most attractive in an environment of low interest rates. When interest rates are high, short-duration projects like strip mining dominate. Since investment decisions are often difficult to reverse, distortions to investment incentives can have a lingering effect long after the initial misallocations.

The current debate in the United States on the booming residential housing market and the appearance of "exotic" mortgage products that backload repayments hinges on the correct pricing of long-term cash flows. If long-term interest rates are low, wage income in the distant future is given a large weight, and even exotic mortgage products seem viable when backed by the large present values of lifetime wage income. For central bankers who must also keep a vigilant eye on overall financial stability, the allocational role of financial market prices thus takes on great significance.

This allocational role is not limited to the yield curve as revealed in the prices of fixed-income securities. Equities that promise high payoffs in the distant future, as do, for example, many technology stocks, are a prime example of investments in long-duration projects. In the same way that high prices of long-duration fixed-income assets push down long-term interest rates, high stock prices lower the implicit discount rate on dividends paid by stocks. Christopher Polk and Paolo Sapienza, as well as Qi Chen, Itay Goldstein, and Wei Jiang, document evidence that investment is sensitive to the information conveyed by stock prices. ${ }^{9}$ Anecdotal stories of formerly staid power companies venturing into telecommunications and other more fashionable business areas and then coming up short of expectations have been a constant theme since the bursting of the technology bubble a few years ago.

Central bankers have a large impact on financial markets. Indeed, it could be argued that the central bank's impact can sometimes be too large. By the nature of the problem, it is difficult to gauge whether the reactions

8. Fisher (1930).

9. Polk and Sapienza (2004); Chen, Goldstein, and Jiang (2005). 
in the financial market are excessive or justified by the fundamentals. However, the paper by George Perry in this volume provides some rare, tantalizing evidence that market prices may be distorted by anticipation of central bank actions. The evidence comes from the contrasting market reactions to two sets of official data on the labor market: the Current Population Survey of households and the Current Employment Statistics survey of nonfarm business payrolls. Perry shows that the two measures are roughly comparable in terms of their ability to track broad labor market conditions, and a simple average of the two does well in combining the informational content of both series.

However, the financial markets certainly do not accord equal weight to the two series. The nonfarm payroll numbers are given far greater weight and are much anticipated by market participants. Michael Fleming and Eli Remolona document the sometimes dramatic reactions in the bond market to the nonfarm payroll numbers. ${ }^{10}$ The fact that the Federal Reserve is known to accord more weight to the nonfarm payroll survey undoubtedly plays on the minds of market participants. Given the importance of others' reactions to news, the fact that other market participants take note of the announcement is reason enough for any one market participant to take note. Thus the contrasting reactions to the two labor market series may be attributable largely to the background presence of the central bank. Keynes's famous "beauty contest" analogy comes to mind, and we will return to this below.

Perry's findings echo a similar phenomenon from an earlier era, namely, the exaggerated reactions to announcements of money stock aggregates during the period after 1979, when the Federal Reserve began to emphasize growth of the money stock as an indicator of the monetary stance. ${ }^{11}$ Although the Federal Reserve had published weekly estimates of monetary aggregates for some time (and continues to do so today), the announcements in the early 1980s became particularly significant with the added importance that the Federal Reserve placed on these aggregates at the time. These money stock announcements became one of the focal events in financial markets, if for no other reason than that significant movements in interest rates were associated with sizable unanticipated changes in the

10. Fleming and Remolona (1999).

11. Roley (1983), Cornell (1983), and Roley and Walsh (1985) have documented the heightened reaction to money stock announcements in the early 1980 s. 
money stock. The market's reactions to such announcements were noticeably larger during the period following the shift in the monetary regime in 1979 than in that preceding it. Roley shows that, "over the $1 \frac{1}{2}$-hour intervals spanning the weekly announcements the variance of the change in the three-month Treasury bill yield in the three years following October 1979 is more than thirty times larger than that in the previous two-year period." ${ }^{12} \mathrm{In}$ particular, the variance of the change in the three-month Treasury bill rate from 3:30 p.m. to 5 p.m. on the announcement day (the announcement always came at 4:10 p.m. on Friday) was 0.0016 for the period from 1977 to September 1979, but then jumped to 0.0536 between October 1979 and October 1982.

When the market understands that the central bank itself is watching the money stock for its policy stance, the strategic interactions among market participants will take center stage. The actual magnitudes will matter less than the fact that the announcements make the numbers common knowledge. The forces at work are similar to the forces that move markets after breaking news stories. The news itself may not be a surprise to some market participants, but the fact that it has become commonly known is news. It is this news that serves as the lightning rod that moves markets.

We now turn to the second channel through which informational efficiency may have an impact on economic welfare. In order for the central bank to steer the economy, it must have good information on the current state of the economy; in particular, it must know how close the economy is to full capacity. If the signals reaching the central bank are not informative, the control problem will be made more difficult.

The flattening of the Phillips curve in many countries in the 1990s is perhaps one indication that this signal value of aggregate prices has deteriorated. Flint Brayton, John Roberts, and John Williams note how the main feature of the Phillips curve - that inflation rises when labor markets tighten - was turned on its head during the economic expansion in the 1990s, when the unemployment rate fell below its long-run average of around 6 percent and then fell below 5 percent, even as inflation fell. ${ }^{13}$ (Figure 1 depicts the unemployment-inflation relation from 1967 to 2002 in both the United States and the United Kingdom.) Replacing unemployment with a measure of capacity utilization does little better to rescue the

12. Roley (1983, p. 344).

13. Brayton, Roberts, and Williams (1999). 
Figure 1. Phillips Curve in the United States and the United Kingdom, 1967-2002

\section{United States}

Inflation (percent change in GDP deflator)

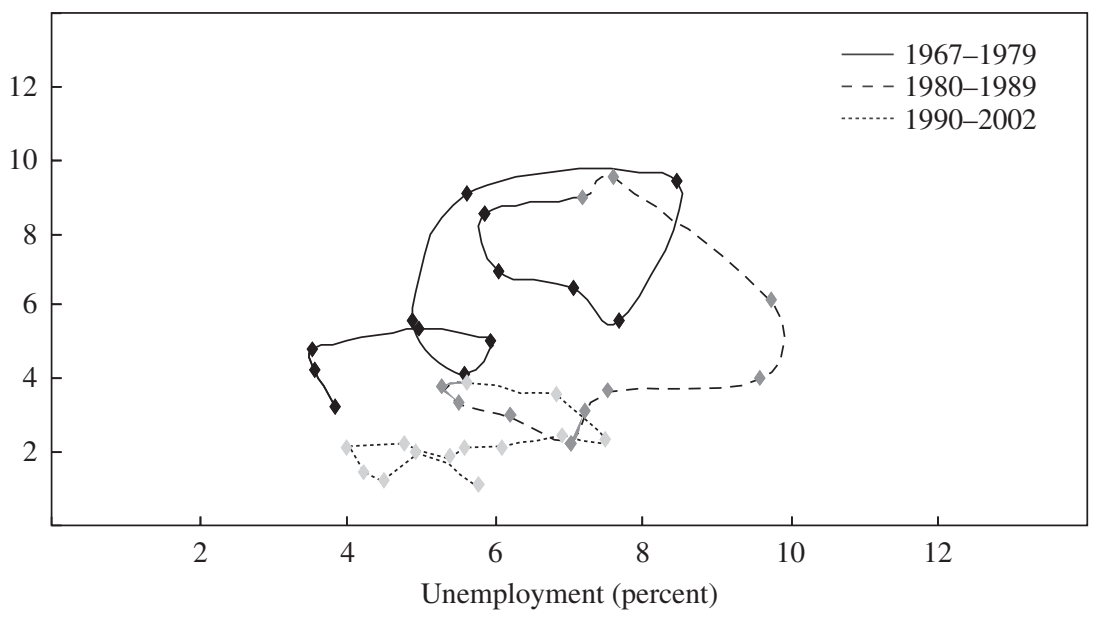

United Kingdom

Inflation (percent change in GDP deflator)

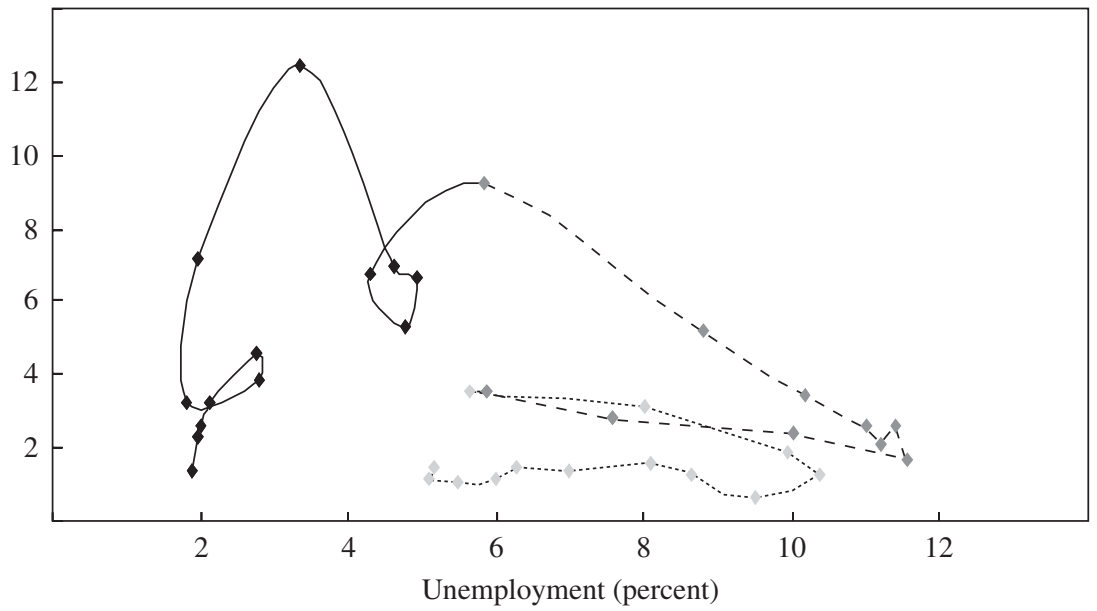

Source: Bean (2003). 
Phillips curve. Although a flattening of the Phillips curve could be interpreted as a shift in the natural rate of unemployment itself, the authors conclude that the explanation that best fits the evidence is that firms' price-cost margins, rather than prices themselves, have taken the brunt of the adjustment. To the extent that costs are part of the fundamentals, and prices are expected to signal cost conditions, the fact that price-cost margins bear the brunt of the adjustment indicates that the signal value of aggregate prices has changed in recent years for the worse. (Here the informational efficiency of prices pertains to goods prices rather than asset prices.)

A telltale sign of the deterioration of the information value of signals would be large revisions to past data. The larger are the revisions to official data, the larger was (in retrospect) the uncertainty about economic conditions at the time.

The Bank of England's experience with data revisions in 2005 is revealing in terms of the difficulties of trying to steer the economy without good information about where the economy is at the moment. Figure 2 shows two fan charts for GDP growth as published in two consecutive issues of the Bank's Inflation Report. ${ }^{14}$ It is immediately evident that GDP growth in early 2005 was revised sharply downward, so that the realized outcome in the first quarter of 2005 fell in the outer tail of the projected distribution of outcomes as given by the top panel. This led to some scrutiny and comment from the press. ${ }^{15}$

Another evident difference is in the shape of the fan chart for the August 2005 report: here the short-range forecasts are given much larger dispersion - the shape is more like a hammer than a fan. The change was introduced to emphasize the uncertainties surrounding current economic conditions. The larger range of outcomes permissible in the short run anticipates possible data revisions.

The August 2005 report describes the divergence between official statistical estimates of GDP and those obtained through business surveys, especially for the services sector. If the survey respondents put excessive weight on the prevailing conventional wisdom about the level of economic activity, it would make the surveys far less informative about current conditions than otherwise. Christopher Sims' notion that economic agents

14. Bank of England (2005).

15. See Geoffrey Dicks, "Bank of England Needs to Re-examine Its Forecasts," Financial Times, August 10, 2005. 
Figure 2. GDP Growth Projections, United Kingdom, 2005-08

May 2005

Percent change in GDP on a year earlier

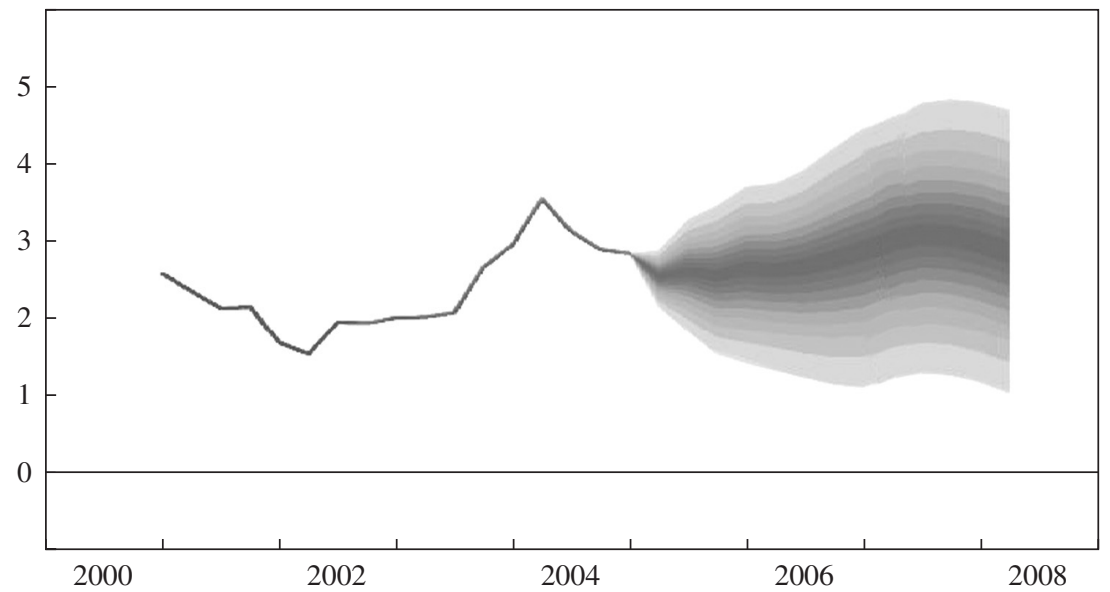

August 2005

Percent change in GDP on a year earlier

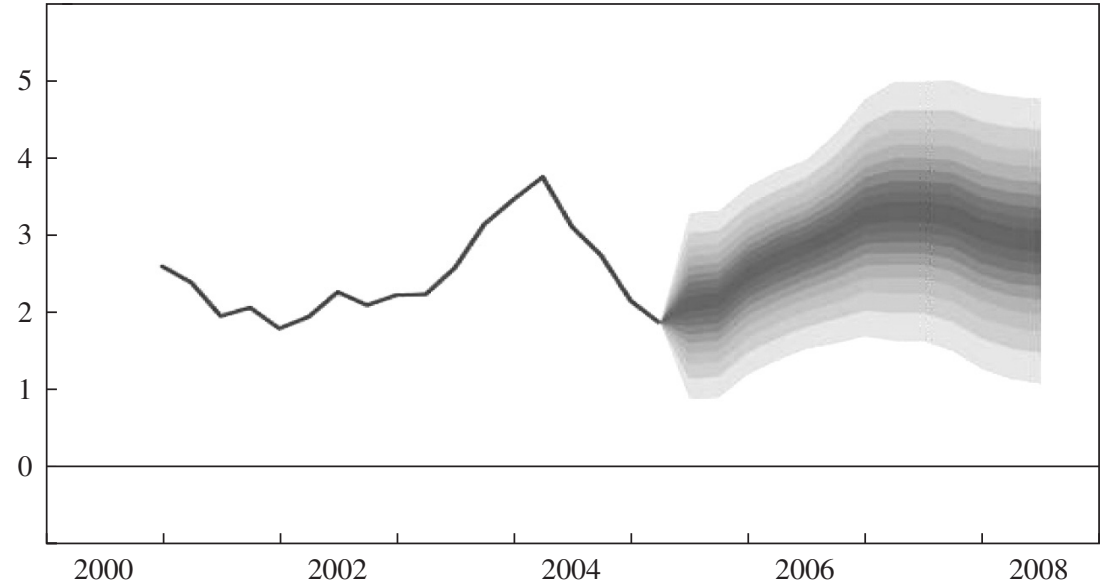

Source: Bank of England Inflation Report, May and August 2005. 
exercise "rational inattention," economizing on their information gathering, would exacerbate this deterioration of information value. ${ }^{16}$

Greater uncertainty about current conditions would be a telltale sign of the deterioration of signal values, and the new convention of drawing a fan chart with a "fatter" base could be seen as an indication of greater awareness of such uncertainty. Strictly speaking, the base of the fan ought to start in the distant past - after all, there is great uncertainty even about the past. The broadening of the base at the current period is a nod to the convention of drawing the fan chart as if current conditions were known. The more the information value of central bank signals deteriorates, the wider will be the base of the fan. Thus one of the key questions we will address is how the precision of the central bank's information changes as it shifts from one disclosure regime to another.

Much evidence has accumulated recently that the publication by central banks of numerical targets for inflation has been associated with a more effective anchoring of inflation expectations. ${ }^{17}$ By squeezing out the corrosive and insidious effects of inflation expectations from the economy, the anchoring of inflation expectations brings large welfare gains. But, we would argue, the flipside of "well-anchored" is "uninformative": price signals that are well anchored are also price signals that have little signal value. They reveal very little to observers looking to them for signs of underlying shifts or trends in the economy. When informational efficiency emerges as a concern, well-anchored expectations cease to be unambiguously desirable.

Gregory Mankiw, Ricardo Reis, and Justin Wolfers examine the dispersion of inflation expectations in survey data and find that inflation expectations have become more concentrated around the mean. ${ }^{18}$ Andrew Levin, Fabio Natalucci, and Jeremy Piger investigate how well the mean inflation expectations have been anchored, also from survey data. ${ }^{19}$ They examine data on inflation forecasts from Consensus Forecasts, Inc., who poll market forecasters twice a year on their forecasts of inflation one to ten years ahead. Levin, Natalucci, and Piger conclude that long-term inflation expectations (looking six to ten years into the future) for a group of inflation-targeting

16. Sims (2003). See also Mackowiak and Wiederholt (2005), who show how Sims' (2003) framework can be used to explain the simultaneous occurrence of persistent average prices and large price shifts in some subsets of goods.

17. Kuttner (2004); Ball and Sheridan (2003).

18. Mankiw, Reis, and Wolfers (2004).

19. Levin, Natalucci, and Piger (2004). 
countries (Australia, Canada, New Zealand, Sweden, and the United Kingdom) have become delinked from actual inflation outcomes, but that there is evidence that they still respond to actual outcomes in the United States and the euro area. They reach their conclusions by running regressions of the following form:

$$
\Delta \pi_{i t}^{q}=\lambda_{i}+\beta \Delta \bar{\pi}_{i t}+\epsilon_{i t},
$$

where $\pi_{i t}^{q}$ is the expectation (formed at date $t$ ) of inflation $q$ years ahead in country $i$, and $\bar{\pi}_{i t}$ is a three-year moving average of inflation in country $i$ ending at date $t$. The coefficient $\beta$ is the focus of the investigation, since it measures the extent to which expectations of future inflation are influenced by the experience of recent inflation. The authors' results indicate that $\beta$ is small and insignificant in the formal inflation-targeting countries, but positive, large, and significant for the non-inflation-targeting countries.

A similar picture emerges from studies that examine the expectations embedded in financial market prices. Refet Gurkaynak, Levin, and Eric Swanson use daily data to examine the market's compensation for expected future inflation as revealed in the difference between forward rates on nominal government bonds and inflation-indexed bonds. ${ }^{20}$ The authors apply this measure of forward inflation compensation to interest rates for U.S., Swedish, and U.K. government bonds to extract estimates of long-run inflation expectations. (Sweden and the United Kingdom are inflationtargeting countries, but the United States is not.) For all three countries the authors find stable long-run inflation expectations, but there are revealing differences. For the United States long-term inflation expectations appear to be influenced by recent experiences of inflation, whereas no such dependence is observed for the United Kingdom or Sweden. These results echo those obtained by Levin, Natalucci, and Piger. They imply that such "excessive" dependence, relative to the baseline model, in the forward inflation premium in the United States occurs because the Federal Reserve does not have a numerical objective for inflation to help tie down long-term inflation expectations. In addition, Gurkaynak, Levin, and Swanson show that long-term forward yield differences in the United States respond excessively to economic news, including surprises in the federal funds rate, a result that the authors attribute to shifts in market participants' views of the Federal

20. Gurkaynak, Levin, and Swanson (2005). 
Reserve's long-term inflation objectives. ${ }^{21}$ To contrast their results for the United States with those for the inflation-targeting countries, the authors show that such excess sensitivity in long-term inflation expectations disappears in the United Kingdom after May 1997, when the Bank of England gained operational independence and monetary policy moved to a formal inflationtargeting regime.

The nature of the problem makes it difficult to bring empirical evidence to bear on whether the central bank's information has, indeed, deteriorated. Thus, at best, our argument is conjectural and speculative. However, we show below that the precision of the central bank's information will depend, in general, on the disclosure regime. The more the central bank discloses, the less precise the signals it receives will be. The fan charts of central bank forecasts become fatter, sometimes considerably so, when it chooses to disclose more. We also return, in closing, to the Bank of England's experience in 2005 for some clues as to what kind of evidence one might look for to help answer the question of informational precision for the central bank.

The theme explored in this paper is the tension between managing expectations and the impaired signal value of both financial market prices and goods prices when expectations are managed. We argue that the quality of the central bank's information is endogenous, and that a central bank that attempts to steer the market's beliefs more vigorously will suffer a greater deterioration in the information value of its signals. We will begin by outlining some technical considerations in developing our argument. But first we revisit a much older debate in economics between Hayek and his socialist contemporaries on the informational role of prices and the role of the market mechanism in aggregating the distributed information of economic agents.

\section{Hayek Revisited}

Friedrich von Hayek's 1945 essay "The Use of Knowledge in Society" has remarkable resonance for today's debate on the informational role of prices. ${ }^{22}$ As is well known, Hayek was arguing against his socialist con-

21. Gurkaynak, Levin, and Swanson (2005); this result is elaborated in Gurkaynak, Sack, and Swanson (2005).

22. Hayek (1945). 
temporaries and other advocates of Soviet central planning. However, his comments are equally relevant for today's debate on central bank transparency. He poses the problem in the following terms:

The peculiar character of the problem of a rational economic order is determined precisely by the fact that the knowledge of the circumstances of which we must make use never exists in concentrated or integrated form, but solely as the dispersed bits of incomplete and frequently contradictory knowledge which all the separate individuals possess. The economic problem of society is thus not merely a problem of how to allocate "given" resources-if "given" is taken to mean given to a single mind which deliberately solves the problem set by these "data." It is rather a problem of how to secure the best use of resources known to any of the members of society, for ends whose relative importance only these individuals know. Or, to put it briefly, it is a problem of the utilization of knowledge not given to anyone in its totality. ${ }^{23}$

Hayek was directing his argument against his contemporaries who argued, from Paretian optimality principles, for the superiority of a centrally planned economy. Chief among this group was Oskar Lange, who developed his arguments in his paper "On the Economic Theory of Socialism," published in two parts in the fledgling Review of Economic Studies in 1936 and 1937. ${ }^{24}$ Lange was an economist in the Paretian tradition who, together with contemporaries such as Abba Lerner and John Hicks, provided the formal apparatus for the development of modern welfare economics. Lange presented one of the first formal arguments for what economists now know as the "two fundamental theorems" of welfare economics. But rather than seeing these results as buttressing the case for the market system, Lange saw them as compelling arguments in favor of central planning and socialism.

For Lange, following Pareto's lead, prices are merely rates of exchange of one good for another, and it is immaterial whether they are set by the central planner or determined in the market by supply and demand. The central planner, however, has the advantage that he or she can act "as if" the Walrasian auctioneer were setting prices, thereby overcoming the distortions of the market economy resulting from imperfect competition, transactions costs, and externalities and achieving a superior allocation of resources.

It was into this debate that Hayek weighed in. Prices, he argued, are not merely the rates of exchange between goods. They have a second role, that

23. Hayek (1945, pp. 519-20).

24. Lange $(1936,1937)$. 
of conveying information on the fundamentals of the economy and the shocks that constantly buffet it. In more modern parlance, price systems are mappings from states of the world to observed market prices, and, as such, they convey information on the shifting fundamentals of the economy that is not available to any one agent or subset of agents. Hayek's argument for the superiority of the market mechanism rests on the premise that the information revealed in prices is likely to be far more illuminating and timely than that which any central planner could possibly hope to amass, let alone maintain and update in a timely manner in line with shifting fundamentals and continuing shocks to the economy.

Hayek's emphasis on the informational role of prices anticipates the modern microeconomic literature on rational expectations equilibria. ${ }^{25}$ His argument is also relevant for the issue of central bank transparency and monetary policy. If the central bank aims to manipulate market expectations in its own image, it cannot at the same time expect the market outcome to serve as the aggregator of the "dispersed bits of incomplete and frequently contradictory knowledge which all the separate individuals possess." The more important the informational role of prices, the greater the tension between managing market expectations and learning from market expectations.

Hayek was not disputing that the central planner may be relatively better informed than any other particular agent in the economy. Indeed, the central planner could have an absolute advantage in this respect over any particular agent. But that is not the point. The point is that prices reveal the collective wisdom of all agents in the economy, by aggregating the diverse information they possess individually. Thus Christina Romer and David Romer's finding that central bank forecasters are better informed than their private sector counterparts is not sufficient to conclude that the central bank does not face the dilemma posed above (although, as we will show later, any formal calculus of the effects must consider the relative informational prowess of the central bank over the individual agents). ${ }^{26}$ The corner shopkeeper serving a small clientele would be hard pressed to match the insights of the central bank forecasting department. However, the shopkeeper is best placed to observe the economic fundamentals ruling in his or her small sliver of the real world. These small slivers, across geographical

25. Grossman (1976); Radner (1979).

26. Romer and Romer (2000). 
regions and sectors of the economy, when pieced together in mosaic fashion, may reveal a far clearer picture than any central planner can hope to achieve.

To be sure, the modern central bank has an awesome array of expertise and technical resources at its disposal. Sims describes vividly how central bank forecasts are the culmination of a major logistical effort, drawing together the results of formal modeling from an array of models as well as the unquantifiable insights of experts on individual sectors. ${ }^{27}$ In this respect, central bank forecasting departments bear some resemblance to the economic planning ministries that Hayek has in his sights. Hayek argues, "We cannot expect that this problem will be solved by first communicating all this knowledge to a central board which, after integrating all knowledge, issues its orders." ${ }^{28}$ The central bank's resources and expertise, as formidable as they are, may fail to match the collective wisdom of the economically active population as a whole.

\section{The Double-Edged Nature of Public Information}

The fundamental debate over the relative superiority of the market mechanism versus central planning that raged in Hayek's time reminds us that the stakes in the economic debate were once much higher than they are today. However, some of the lessons from the Hayek-Lange debate are applicable even in the more modest arena of central bank transparency and monetary policy. Rather than presenting a stark choice between socialism and the market economy, the issues arise in the role of public information in an economy with distributed knowledge — an economy where each agent has a "window" on the world, each with a slightly different perspective, and each with a possible relative advantage in ascertaining the truth about some smaller sliver of the real world.

In general, an individual facing a choice under uncertainty will benefit from gaining greater access to information that reduces the uncertainty, since better information permits actions that are better suited to the circumstances. This conclusion is unaffected by whether the incremental information is public (in the sense of being shared by everyone) or private (available only to that individual).

27. Sims (2002).

28. Hayek (1945, p. 524). 
But there are reasons why improved public information, although privately valuable to the decisionmaker receiving it, might not be valuable to society. If the private information of some market participants is to be revealed to others, that information must be reflected in market outcomes. But if public information leads market participants to ignore or downplay their own private information in their actions, the market will reveal less new information about market conditions. Thus public signals generate an informational externality.

This effect is further exacerbated if decisionmakers' interests are intertwined in such a way that a decisionmaker is an interested party in the actions taken by others. Public information in such contexts has attributes that make it a double-edged instrument. On the one hand, public information conveys information concerning the underlying fundamentals, as before. However, it also serves as a focal point for the beliefs of the group as a whole and thus serves a powerful coordination role. The "sunspots" literature has emphasized how even signals that are "extrinsic," having no direct bearing on the underlying fundamentals, may nevertheless serve to coordinate the actions of individual agents because of their very public nature. To the extent that public information allows coordination on good outcomes, greater precision of public information may be beneficial. But, equally, that coordination could be coordination on less desirable outcomes. With sunspots, some indeterminacy would always rule.

In most cases of interest, public information about monetary policy is not merely a sunspot, however; it conveys important information concerning the economic fundamentals. The question then is how the coordination effect of public information will affect the inferences drawn by individual economic agents, and how their intertwined interests will affect their individual incentives and the collective outcome that results from their acting on these incentives.

When there is the potential for a strong consensus to prevail or a conventional wisdom to take hold, individual incentives may become distorted in such a way as to reduce the informational value of economic outcomes. Central bank pronouncements may then serve as a lightning rod, reinforcing the conventional wisdom or consensus and suppressing dissent from those individuals whose own private signals tell them that the conventional wisdom is flawed. When individual incentives are thus eroded, the signals that would otherwise emerge from dissenting voices to undermine the flawed consensus may be muted, serving to perpetuate the flawed consensus. 
In an earlier paper, ${ }^{29}$ we explored the trade-offs that result in such a setting by examining the outcome of a collective decision problem reminiscent of Keynes's celebrated metaphor of the beauty contest. Keynes drew a parallel between financial markets and a form of newspaper competition of his day that invited readers to pick the six prettiest faces from 100 photographs. ${ }^{30}$ Readers won by picking the set of faces that "most nearly corresponds to the average preferences of the competitors as a whole." Under these rules, Keynes noted, a reader would win by anticipating which faces would become the popular choice, rather than by choosing those that the reader found most attractive. If individual readers voted on the basis of their own sincerely held judgments, the aggregate outcome would reveal much about the true collective judgment of the contestants as a whole. However, the more the contestants vote on the basis of "anticipating what average opinion expects average opinion to be," the more the aggregate vote will reflect the outcome of this second-guessing game among the contestants.

Now imagine how much worse the distortion would be if a widely watched authority figure were to weigh in, offering his or her public judgment on the faces in the photographs. The authority's judgment may or may not be sound. What counts is that his or her pronouncements reach a wide audience, and that everyone knows that his or her pronouncements reach a wide audience. For this reason alone, the authority's public judgment would serve as a powerful rallying point around which average opinion could coalesce. Once the public pronouncement has been issued, it would be futile for any reader to expend effort in scouring the faces in the photographs, to form an independent opinion of their fundamental attributes. Knowing that others would likewise regard this as futile and will not gainsay the authority figure, such a reader would have little incentive to expend effort in reaching an independent judgment. The aggregate outcome would thus reveal little about the genuine collective judgments of the individual contestants, but instead would be dominated by the public pronouncement. The signal value of the aggregate vote would thus be severely impaired.

Arguably, central bank transparency raises similar issues. When the central bank issues regular pronouncements on the economic outlook and publishes its forecasts of the output gap and the path of its policy rate, such pronouncements provide a powerful rallying point around which market

29. Morris and Shin (2002).

30. Keynes (1936). 
expectations can coalesce. The more market participants consider the beliefs of other market participants, the greater will be the impact of the central bank's pronouncements in determining the aggregate market outcome.

The dilemma for monetary policy transparency is that such pronouncements by the central bank will, invariably, also offer genuine and valuable insight on the current and future state of the economy. But, however sound as a guide to the underlying fundamentals, the central bank's pronouncements are even better as guides to what average opinion will be. As a result, traders give the opinions of central bankers undue weight and place less weight on their own independent assessments of the economy. Public pronouncements can thus crowd out private opinions, and the market may cease to function as a way of aggregating and revealing diverse, private judgments about the world in the way that Hayek envisaged.

Most interestingly (and most disturbingly), consider how the problem is altered when the central bank becomes even better informed. Suppose that the central bank, in light of the disappointing performance of its forecasts, decides to beef up its forecasting effort by recruiting yet more experts and pouring in yet more resources. Paradoxically, the problem may become worse, not better, when the central bank's competence in reading the economy improves. There are two countervailing effects. On the one hand, the improved ability of the central bank to read the economy will provide betterquality information to other economic agents. However, the better the central bank becomes at reading the economy, the more authority it gains in the eyes of those other agents. As the central bank's pronouncements become more authoritative, its ability to serve as the rallying point for coordinating market expectations becomes stronger, suppressing further the channel through which dissenting agents can express their views. The net effect of improved central bank transparency is thus ambiguous. This is one aspect of what might be called the "paradox of transparency."

\section{Elements of a Theory}

The simplest way to motivate the problem is in terms of a decision problem akin to Keynes's beauty contest, although it will be important to show how real-world economic decisions can be understood within a similar framework. We will return to the economic applications after seeing how the key effects enter in a simpler, abstract decision. 
Suppose that there are many small agents, each of whom faces the problem of tailoring his or her action to the underlying state $\theta$, but also tries to second-guess the decisions of the other agents. Suppose that each agent $i$ follows the decision rule

$$
a_{i}=(1-r) E_{i}(\theta)+r E_{i}(\bar{a}),
$$

where $\bar{a}$ is the average action in the population, and $E_{i}\left({ }^{\circ}\right)$ is the expectations operator for player $i$. Each agent puts a positive weight on the expected fundamental state $E(\theta)$ and on the expected actions of others and chooses a weighted average of the two. The parameter $r$, where $0<r<1$, indicates the extent to which agent $i$ is motivated by the concern to secondguess the actions of others. If $r$ is large (close to 1), decisions are influenced predominantly by anticipation of what others do, rather than by one's own perception of the fundamentals.

\section{The Public Information Benchmark}

In the simplest case, if $\theta$ is commonly known, equilibrium entails $a_{i}=$ $\theta$ for all $i$. When instead agents face uncertainty concerning $\theta$ but have access to a source of information shared by all, their actions approximate $\theta$ most closely when uncertainty is small. Suppose $\theta$ is drawn from an (improper) uniform prior over real numbers, but agents observe the single public signal

$$
y=\theta+\eta,
$$

where $\eta$ is normally distributed and independent of $\theta$, with mean zero and variance $\sigma_{\eta}^{2}$. The signal $y$ is "public" in the sense that the actual realization of $y$ is common knowledge among all agents. They choose their actions after observing the realization of $y$. Conditional on $y$, all agents believe that $\theta$ is distributed normally with mean $y$ and variance $\sigma_{\eta}^{2}$. Hence, agent $i$ 's optimal action is

$$
a_{i}(y)=(1-r) E(\theta \mid y)+r \int_{0}^{1} E\left(a_{j} \mid y\right) \mathrm{d} j,
$$

where $a_{i}(y)$ denotes the action taken by agent $i$ as a function of $y$. Since $E(\theta \mid y)=y$, and since everyone can condition on $y$, we have $E\left(a_{j} \mid y\right)=a_{j}(y)$, so that 


$$
a_{i}(y)=y
$$

for all $i$. The average action is then $y$, and the distance between $a_{i}$ and $\theta$ is

$$
E\left[(y-\theta)^{2} \mid \theta\right]=\sigma_{\eta}^{2} .
$$

Thus the less noise in the public signal, the closer is the action to the fundamentals. We will now contrast this with the Hayekian case in which each agent has his or her own "window on the world."

\section{The Hayekian Case}

Consider now the case where, in addition to the public signal $y$, agent $i$ observes the realization of a private signal:

$$
x_{i}=\theta+\epsilon_{i},
$$

where noise terms $\epsilon_{i}$ are normally distributed with zero mean and variance $\sigma_{\epsilon}^{2}$, independent of $\theta$ and $\eta$, so that $E\left(\epsilon_{i} \epsilon_{j}\right)=0$ for $i \neq j$. The private signal of one agent is not observable by the others; each agent has a privileged view of his or her own small sliver of the world.

As before, the agents' decisions are made after observing their signals. Denote by $\alpha$ and $\beta$ the precision of the public and the private information, respectively, where

$$
\left\{\begin{array}{l}
\alpha=\frac{1}{\sigma_{\eta}^{2}} \\
\beta=\frac{1}{\sigma_{\epsilon}^{2}} .
\end{array}\right.
$$

Then, based on both private and public information, agent $i$ 's expected value of $\theta$ is

$$
E_{i}(\theta)=\frac{\alpha y+\beta x_{i}}{\alpha+\beta}
$$

One simple way to solve for the equilibrium is to posit that actions are a linear function of signals. We will follow this with a demonstration that this linear equilibrium is the unique equilibrium, which also gives important 
insights into the double-edged nature of public information. Thus, as the first step, suppose that each agent follows a linear rule,

$$
a_{j}=\kappa x_{j}+(1-\kappa) y
$$

for some constant $\kappa$. Then agent $i$ 's conditional estimate of the average expected action across all agents is

$$
\begin{aligned}
E_{i}(\bar{a}) & =\kappa\left(\frac{\alpha y+\beta x_{i}}{\alpha+\beta}\right)+(1-\kappa) y \\
& =\left(\frac{\kappa \beta}{\alpha+\beta}\right) x_{i}+\left(1-\frac{\kappa \beta}{\alpha+\beta}\right) y
\end{aligned}
$$

Agent $i$ 's optimal action is

$$
\begin{aligned}
a_{i} & =(1-r) E_{i}(\theta)+r E_{i}(\bar{a}) \\
& =(1-r)\left(\frac{\alpha y+\beta x_{i}}{\alpha+\beta}\right)+r\left[\left(\frac{\kappa \beta}{\alpha+\beta}\right) x_{i}+\left(1-\frac{\kappa \beta}{\alpha+\beta}\right) y\right] \\
& =\left[\frac{\beta(r \kappa+1-r)}{\alpha+\beta}\right] x_{i}+\left[1-\frac{\beta(r \kappa+1-r)}{\alpha+\beta}\right] y .
\end{aligned}
$$

Comparing coefficients in equations 9 and 10, we therefore have

$$
\kappa=\frac{\beta(r \kappa+1-r)}{\alpha+\beta},
$$

from which we can solve for $\kappa$. The equilibrium action $a_{i}$ is given by

$$
a_{i}=\frac{\alpha y+\beta(1-r) x_{i}}{\alpha+\beta(1-r)},
$$

and the average action is

$$
\bar{a}=\frac{\alpha y+\beta(1-r) \theta}{\alpha+\beta(1-r)} .
$$

First observe that the larger is $\alpha$, the further away is the average action from $\theta$. This is true even if $r=0$. However, if $r>0$, even less weight is put on the true state and even more weight on the public signal. 
Together with Franklin Allen, we have developed this theme in an asset pricing model where the price of an asset today is the average expectation of tomorrow's price. ${ }^{31}$ Average expectations fail to satisfy the "law of iterated expectations." That is to say, the average expectation today of the average expectation tomorrow of future payoffs is not the same thing as the average expectation of future payoffs. In a Hayekian environment, the failure of the law of iterated expectations follows a systematic pattern that puts too much weight on shared information-conventional wisdom or other public signals, including past prices. Past prices, in particular, receive too much weight relative to the statistically optimal weight in a frictionless world. Given the importance of the failure of the law of iterated expectations, it is illuminating to dwell briefly on how the example sketched above can be shown to be an example of such a failure.

\section{Higher-Order Beliefs}

Recall that agent $i$ 's decision rule is

$$
a_{i}=(1-r) E_{i}(\theta)+r E_{i}(\bar{a}) .
$$

Substituting and writing $\bar{E}(\theta)$ for the average expectation of $\theta$ across agents, we have

$$
\begin{aligned}
a_{i} & =(1-r) E_{i}(\theta)+(1-r) r E_{i}(\bar{E}(\theta))+(1-r) r^{2} E_{i}\left(\bar{E}^{2}(\theta)\right)+\ldots \\
& =(1-r) \sum_{k=0}^{\infty} r^{k} E_{i}\left(\bar{E}^{k}(\theta)\right) .
\end{aligned}
$$

To evaluate this expression, one must solve explicitly for $E_{i}\left(\bar{E}^{k}(\theta)\right)$. Recall that agent $i$ 's expected value of $\theta$ is

$$
E_{i}(\theta)=\frac{\alpha y+\beta x_{i}}{\alpha+\beta} .
$$

Thus the average expectation of $\theta$ across agents is

$$
\bar{E}(\theta)=\int_{0}^{1} E_{i}(\theta) \mathrm{d} i=\frac{\alpha y+\beta \theta}{\alpha+\beta} .
$$

31. Allen, Morris, and Shin (forthcoming). 
Now agent $i$ 's expectation of the average expectation of $\theta$ across agents is

$$
\begin{aligned}
E_{i}(\bar{E}(\theta)) & =E_{i}\left(\frac{\alpha y+\beta \theta}{\alpha+\beta}\right) \\
& =\frac{\alpha y+\beta\left(\frac{\alpha y+\beta x_{i}}{\alpha+\beta}\right)}{\alpha+\beta} \\
& =\frac{\left[(\alpha+\beta)^{2}-\beta^{2}\right] y+\beta^{2} x_{i}}{(\alpha+\beta)^{2}},
\end{aligned}
$$

and the average expectation of the average expectation of $\theta$ is

$$
\begin{aligned}
\bar{E}^{2}(\theta) & =\bar{E}(\bar{E}(\theta)) \\
& =\frac{\left[(\alpha+\beta)^{2}-\beta^{2}\right] y+\beta^{2} \theta}{(\alpha+\beta)^{2}} .
\end{aligned}
$$

Higher-order expectations put more weight on the (noisy) public information at the expense of the truth. Not only does the law of iterated expectations fail; it fails in a systematic way where higher-order expectations are less informative about $\theta$. By induction we have $\bar{E}^{k}(\theta)=\left(1-\mu^{k}\right) y+\mu^{k} \theta$, where $\mu=\beta /(\alpha+\beta)$, and

$$
\begin{aligned}
a_{i} & =(1-r) \sum_{k=0}^{\infty} r^{k}\left[\left(1-\mu^{k+1}\right) y+\mu^{k+1} x_{i}\right] \\
& =\left[1-\frac{\mu(1-r)}{1-r \mu}\right] y+\left[\frac{\mu(1-r)}{1-r \mu}\right] x_{i} \\
& =\frac{\alpha y+\beta(1-r) x_{i}}{\alpha+\beta(1-r)} .
\end{aligned}
$$

This is exactly the unique linear equilibrium we identified earlier.

\section{Economic Interpretations of the Decision Rule}

The decision rule in equation 2 , which was motivated by the beauty contest analogy, can be given more familiar macroeconomic underpinnings by appealing to the "island economy" model of Robert Lucas and Edmund 
Phelps, ${ }^{32}$ although, for reasons to be discussed below, we favor another interpretation of the decision rule. Suppose that there are a large number of small islands, which can be interpreted either as distinct geographical regions or as different sectors of the economy. There is a single good in this archipelago, and the supply of this good on island $i$ is denote by $q_{i}^{s}$. The supply of the good is increasing in the difference between the price on island $i$ and the perceived average price across all islands. In particular, we take the linear supply function

$$
q_{i}^{s}=b\left[p_{i}-E_{i}(\bar{p})\right],
$$

where $p_{i}$ is the price on island $i, \bar{p}$ is the average price across all islands, and $b>0$ is a supply parameter. The expectations operator $E_{i}(\cdot)$ denotes the expectation with respect to the information available to residents of island $i$.

The demand for the good on island $i$ is a decreasing linear function of the price on the island, but it also depends on the best estimate of some underlying fundamental variable $\theta$. In the original treatment of this problem by Lucas and Phelps, $\theta$ is construed as being the money supply and is under the central bank's control. Demand on island $i$ is thus given by

$$
q_{i}^{d}=E_{i}(\theta)-p_{i},
$$

where $\theta$ is the money supply. Market clearing then implies

$$
p_{i}=(1-r) E_{i}(\theta)+r E_{i}(\bar{p}),
$$

where $r=b /(b+1)$. This is the pricing rule obtained by Phelps, ${ }^{33}$ which extends the standard Lucas-Phelps island economy model by incorporating a role for the expectations of prices set on other islands. Thus we retrieve the beauty contest decision rule.

Although the outward form of equation 18 conforms to the beauty contest decision rule, the fundamental variable $\theta$ in the original version of the island economy model is something that the central bank has full control over. Thus learning about $\theta$ is not an issue, and so the informational role of prices has no part to play in the analysis.

A more appropriate interpretation of the pricing rule in equation 18 is in terms of the price-setting decisions of firms that have some market power

32. Lucas (1972, 1973); Phelps (1970).

33. Phelps (1983). 
due to imperfect substitutability between goods. ${ }^{34}$ In this context $\theta$ represents the underlying marginal cost conditions for the firms, which also correspond to the output gap under some simplifications. ${ }^{35}$ Firms care about the prices set by other firms because there is price competition across firms. Woodford considers pricing rules for firms of the form

$$
p_{i}=E_{i}(p)+\xi E_{i}(\chi),
$$

where $p_{i}$ is the $(\log )$ price set by firm $i, p$ is the average price across firms, $\chi$ is marginal cost (in real terms), and $\xi$ is a constant between 0 and $1 .{ }^{36}$ The operator $E_{i}$ denotes the conditional expectation with respect to firm $i$ 's information set. The parameter $\xi$ is related to the elasticity of substitution between goods, and it becomes small as the economy becomes more competitive ${ }^{37}$ An active literature has developed exploring the Hayekian theme in the context of an imperfectly competitive economy. ${ }^{38}$

Rewriting equation 19 in terms of nominal marginal cost, defined as $\theta \equiv \chi+p$, we have

$$
p_{i}=(1-\xi) E_{i}(p)+\xi E_{i}(\theta),
$$

yielding another way to derive the beauty contest decision rule.

The examples above pertain to the pricing of goods, but many of the properties of beauty contests arise also in the context of financial market pricing. Financial market prices present the additional complication that they are forward looking: the price today equals the discounted expected payoff at some future date. Nevertheless, the excessive impact of public information can be shown, at the cost of some additional apparatus. Allen, Morris, and Shin derive asset pricing formulas of the form

$$
p_{t}=\bar{E}_{t} \bar{E}_{t+1} \cdots \bar{E}_{t+h} \theta_{t+h}-\omega s_{t},
$$

34. Woodford (2003a) has popularized this interpretation of the beauty contest rule.

35. Galí and Gertler (1999).

36. Woodford (2003a).

37. Woodford (2003a). Townsend (1983) discusses similar linear rules but in the context of investment.

38. See Adam (2003), Amato and Shin (forthcoming), Hellwig (2002, 2004), and Ui (2003). See also Kasa (2000) and Pearlman and Sargent (2005). The latter show how the problem can sometimes be reduced to the case with common knowledge. Similar issues arise in the context of asset pricing: see Allen, Morris, and Shin (forthcoming) and Bacchetta and Van Wincoop (2003, 2004). 
where $p_{t}$ is the price of a financial asset at time $t, \theta_{t+h}$ is the fundamental payoff at time $t+h, \omega$ is a constant, and $s_{t}$ is the asset supply, with a mean of zero. ${ }^{39}$ Thus the price of an asset today is the average expectation today of the average expectation tomorrow, and so on, of the eventual realized fundamentals.

The law of iterated expectations fails also in this context, and the direction of the failure is toward excessive influence of public information. Asset pricing applications present some technical difficulties, such as the fact that past (and even current) prices constitute public signals that enter into the information sets of traders. Thus the innocuous-looking notation $\bar{E}_{t}$ actually conceals much subtlety.

However, the broad conclusions are the same as for the static beauty contest. Public information has a disproportionate impact on financial market prices. The precise sense in which this is true is that the market price deviates systematically from the average expectation of the fundamental value, and the bias is always toward commonly shared information, including past prices. More formally,

$$
\begin{aligned}
p_{t} & =\bar{E}_{t} \bar{E}_{t+1} \cdots \bar{E}_{t+h} \theta_{t+h}-\omega s_{t} \\
& \neq \bar{E}_{t}\left(\theta_{t+h}\right)-\omega s_{t},
\end{aligned}
$$

and the distance between $p_{t}$ and the expectation of $\theta_{t+h}$ based purely on public information is smaller than the distance between $\bar{E}_{t} \theta_{t+h}$ and the expectation of $\theta_{t+h}$ based purely on public information. Thus the key features of the overreaction to public information apply to financial markets also.

\section{The Precision of Endogenous Information}

So far we have treated the precision $\alpha$ of public information as given. But the information available to central banks derives from outcomes in the economy itself and hence is the result of actions taken by individual economic agents. To the extent that individuals' decisions are affected by public information, we can expect the signal values of the resulting outcomes to be sensitive to the disclosure regime.

We show that this is indeed the case. The information precision of a central bank that issues regular forecasts is lower than that of a central bank

39. Allen, Morris, and Shin (forthcoming). 
that simply tracks the evolution of the fundamentals through its signals. We postpone a discussion of the potential welfare effects of such impaired signal precision until the next section, and instead concentrate here on why the information value deteriorates when a central bank discloses more.

Time is discrete and indexed by $t \in\{\ldots,-2,-1,0,1,2, \ldots\}$. The fundamentals $\left\{\theta_{t}\right\}$ evolve as a Gaussian random walk:

$$
\theta_{t}=\theta_{t-1}+\phi_{t},
$$

where $\left\{\phi_{t}\right\}$ are independent standard normal innovations.

At each date a new generation of private sector actors observe a noisy signal of the fundamentals as of that date, together with any present and past disclosures by the central bank. Individual $i$ 's noisy signal in generation $t$ is given by

$$
x_{i t}=\theta_{t}+\epsilon_{i t},
$$

where $\epsilon_{i t}$ are independently and identically distributed (i.i.d.) normal across individuals and across generations with precision $\beta$.

We assume a sparse information set for the individual at date $t$ (for instance, there is no access to the private information of previous generations). But we do this as a way of setting the basic level of information to which the central bank can add by disclosing its own estimates and forecasts, if it chooses to. Extending the model to encompass richer settings would be worthwhile for specific applications.

The private sector agents play a beauty contest game, following the decision rule

$$
a_{i t}=(1-r) E_{i t}\left(\theta_{t}\right)+r E_{i t}\left(\bar{a}_{t}\right),
$$

where $\bar{a}_{t}$ is the average action across individuals at date $t$.

The central bank observes a noisy signal about what the private sector individuals did in the previous period. At date $t$ that signal is

$$
z_{t}=\bar{a}_{t-1}+\psi_{t},
$$

where $\left\{\psi_{t}\right\}$ are i.i.d. Gaussian noise terms independent of all other random variables, and with variance $1 / \gamma$.

The central bank's information set at date $t$ is the collection of all past signals $\left\{\ldots, z_{t-2}, z_{t-1}, z_{t}\right\}$. We are interested in the central bank's information precision at date $t$ as measured by 


$$
\operatorname{Var}\left(\theta_{t} \mid z_{t}, z_{t-1}, \cdots\right)
$$

Compare two possible regimes. In the first the central bank makes no disclosures but simply tracks the fundamentals through its signals. In the second the central bank discloses its best estimates of the fundamentals. Since the fundamentals follow a random walk, the disclosure of the central bank's estimate of $\theta$ is tantamount to issuing forecasts of future values of $\theta$ at all horizons.

\section{The Case without Disclosure}

In the first case, since there is a continuum of private sector agents, and they receive i.i.d. signals conditional on the fundamentals, the average action $\bar{a}_{t}$ fully reveals the true fundamental state $\theta_{t}$. Thus the central bank's signals are given by

$$
z_{t}=\theta_{t-1}+\psi_{t}
$$

We write $\hat{z}_{t}$ as the linear estimate of $\theta_{t}$ based on $\left\{z_{t}, z_{t-1}, z_{t-2}, \ldots\right\}$, and let $\alpha_{t}$ be the precision of this estimate as measured by $1 / \operatorname{Var}\left(\theta_{t} \mid z_{t}, z_{t-1}, \ldots\right)$. Then, on observing $z_{t+1}$ at date $t+1$, the linear estimate of $\theta_{t}$ is

$$
\frac{\alpha_{t} \hat{z}_{t}+\gamma z_{t+1}}{\alpha_{t}+\gamma}
$$

with precision $\alpha_{t}+\gamma$. Since $\theta_{t+1}=\theta_{t}+\phi_{t+1}$, we have a recursive formula for the central bank's information precision over time, namely,

$$
\begin{aligned}
\frac{1}{\alpha_{t+1}} & =\operatorname{Var}\left(\theta_{t+1} \mid z_{t+1}, \hat{z}_{t}\right) \\
& =1+\frac{1}{\alpha_{t}+\gamma} .
\end{aligned}
$$

The steady-state information precision in the nondisclosure case is thus the value of $\alpha$ that solves

$$
\alpha\left(1+\frac{1}{\alpha+\gamma}\right)=1
$$




\section{The Case with Disclosure}

In the second case, where the central bank discloses its signals to the individual agents, the information set of agent $i$ in generation $t$ is

$$
\left\{x_{i t}, z_{t}, z_{t-1}, \cdots\right\} \text {. }
$$

Let $\hat{z}_{t}$ be the linear estimate of $\theta_{t}$ based on the central bank's disclosures only, and let $\alpha_{t}$ be the precision of this estimate. Then this individual will take action as follows:

$$
a_{i t}=\frac{\alpha_{t} \hat{z}_{t}+(1-r) \beta x_{i t}}{\alpha_{t}+(1-r) \beta}
$$

By taking the average across individuals in equation 30 , the average action is

$$
\begin{array}{r}
\bar{a}_{t}=\frac{\alpha_{t} \hat{z}_{t}+(1-r) \beta \theta_{t}}{\alpha_{t}+(1-r) \beta} \\
z_{t+1}-\psi_{t+1}=\frac{\alpha_{t} \hat{z}_{t}+(1-r) \beta \theta_{t}}{\alpha_{t}+(1-r) \beta} .
\end{array}
$$

Solving for $\theta_{t}$ as a function of $\hat{z}_{t}, z_{t+1}$,

$$
\theta_{t}=\left[1+\frac{\alpha_{t}}{(1-r) \beta}\right] z_{t+1}-\frac{\alpha_{t}}{(1-r) \beta} \hat{z}_{t}-\left[1+\frac{\alpha_{t}}{(1-r) \beta}\right] \psi_{t+1} .
$$

Thus the incremental information value to the central bank from observing $z_{t+1}$ comes from the signal

$$
s_{t+1} \equiv\left[1+\frac{\alpha_{t}}{(1-r) \beta}\right] z_{t+1}-\frac{\alpha_{t}}{(1-r) \beta} \hat{z}_{t},
$$

which is orthogonal to $\left\{z_{\tau}\right\}_{\tau \leq t}$. The precision of $s_{t+1}$ is

$$
\gamma\left[1+\frac{\alpha_{k}}{(1-r) \beta}\right]^{-2},
$$

which we denote by $\hat{\gamma}_{t}$. 
Since $\hat{\gamma}_{t} \leq \gamma$, we can conclude that the incremental information value to the central bank of observing its signal $z_{t+1}$ is lower in the disclosure case. Moreover, this incremental information value is lower, the higher was the central bank's overall precision $\alpha_{t}$ in the previous period. In other words, raising the central bank's overall information precision has the effect of lowering the value of its subsequent signal. The intuition is that increased precision at $t$ intensifies the beauty contest and reduces the information value of the average action. This then lowers the information precision of the signal arriving at $t+1$.

At date $t+1$ the central bank's linear estimate of $\theta_{t}$ is

$$
\frac{\alpha_{t} \hat{z}_{t}+\hat{\gamma}_{t} s_{t+1}}{\alpha_{t}+\hat{\gamma}_{t}}
$$

with precision $\alpha_{t}+\hat{\gamma}_{t}$. Since $\theta_{t+1}=\theta_{t}+\phi_{t+1}$, we have a recursive formula for the central bank's information precision in the disclosure case:

$$
\begin{aligned}
\frac{1}{\alpha_{t+1}} & =1+\frac{1}{\alpha_{t}+\hat{\gamma}_{t}} \\
& =1+\frac{1}{\alpha_{t}+\gamma\left[\frac{(1-r) \beta}{\alpha_{t}+(1-r) \beta}\right]^{2}} .
\end{aligned}
$$

The steady-state information precision in the disclosure case is the value of $\alpha$ that solves

$$
\alpha\left\{1+\frac{1}{\alpha+\gamma\left[\frac{(1-r) \beta}{\alpha+(1-r) \beta}\right]^{2}}\right\}=1 \text {. }
$$

\section{Comparing the Regimes}

Comparing the steady-state information precision levels in the two regimes given by equations 28 and 34, we can see that steady-state precision is lower under the disclosure regime, since the value of the expression in curved brackets in equation 34 is greater than $1+[1 /(\alpha+\gamma)]$. For parameter 
Figure 3. Precision of Public Information by Type of Regime ${ }^{a}$

Precision $(\alpha)$, maximum $=1.0$

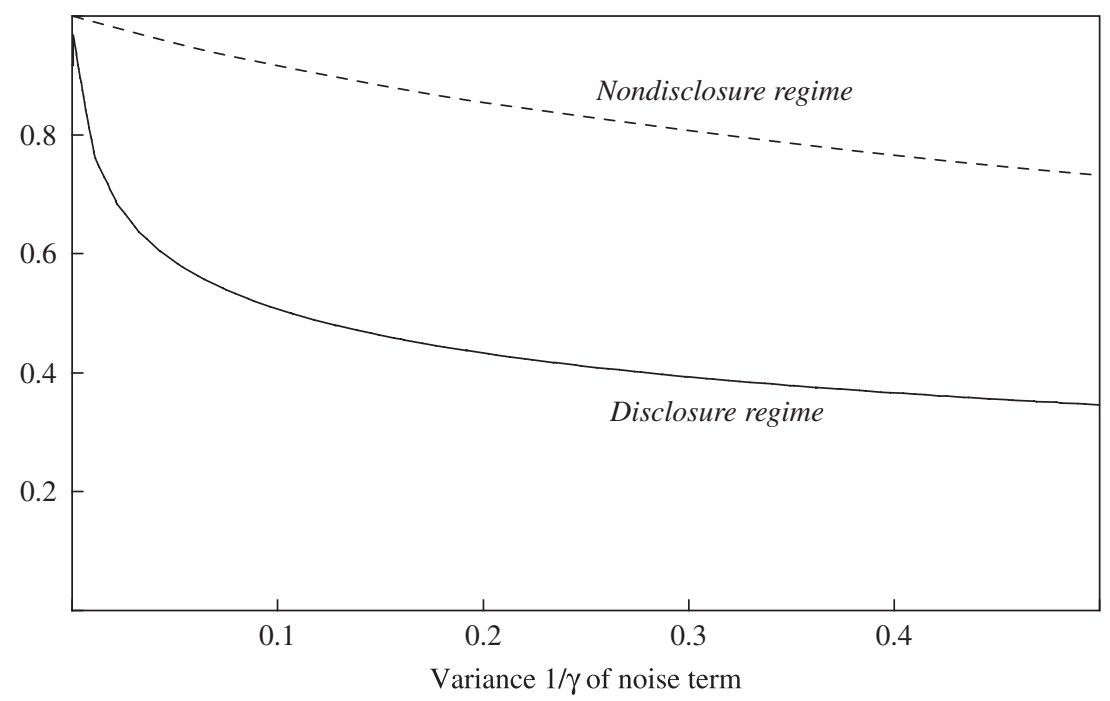

Source: Authors' calculations using the model described in the text

a. $\alpha$ is the precision of public information and $\gamma$ the precision of the central bank's signal $z_{t}$ as explained in the text.

values $r=0.85$ and $\beta=1,{ }^{40}$ we can plot in figure 3 the steady-state information precision $\alpha$ as a function of the variance $1 / \gamma$ of the noise term $\psi$. The central bank has higher information precision in the nondisclosure case. In both cases this precision can be raised to the upper bound of 1 by reducing the variance of the noise, but the disclosure case requires very little noise to get close to the upper bound.

It is worth noting that the deterioration of the central bank's signal value under the disclosure regime holds even when $r=0$, so that there are no coordination elements, although coordination elements exacerbate the effect. We return to this issue below.

It is also apparent from the implicit formula in equation 34 for steadystate $\alpha$ that the central bank's information precision is a function of the private sector agents' information precision. This is intuitively clear, since

40. The value $r=0.85$ is implied by $\xi=0.15$ in the imperfect competition interpretation of the beauty contest rule. See Woodford (2003b) for a discussion of the magnitude of $\xi$. 
Figure 4. Precision of Public and Private Information in Disclosure Regime ${ }^{\mathrm{a}}$

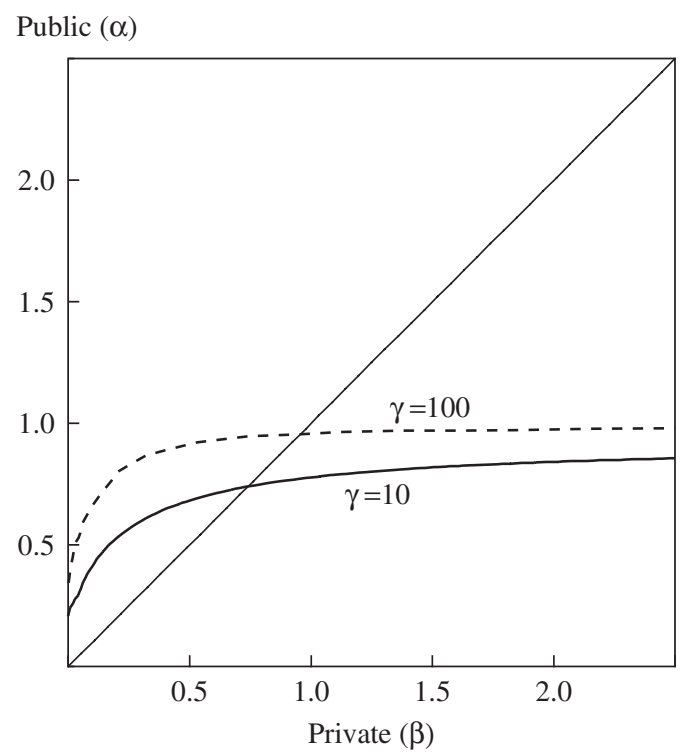

Source: Authors' calculations using the model described in the text. a. $\alpha$ is the precision of public information and $\beta$ the precision of private information as explained in the text.

the central bank learns by observing what the individual agents do. The reason $\beta$ enters in this relation is that the aggregate actions $\bar{\alpha}_{t}$ are revealing only to the extent that private agents put weight on their own private signals. The more informative their private signals, the greater the information value of the aggregate action. In this sense the central bank's information value is dependent on (and derivative of) the private sector agents' information precision.

Figure 4 plots $\alpha$ as a function of $\beta$ for varying values of the noise $\psi_{t}$ in the central bank's signal (holding other parameter values the same as in figure 3). The central bank's information precision is increasing in the private sector's information precision, but $\alpha$ can lie below $\beta$, especially when $\beta$ is large. One reason is that, whereas private sector agents have contemporaneous information about $\theta_{t}$ from their signals (say, by observing a signal about their current marginal cost), the central bank's signal comes with some delay, and the innovation to $\theta_{t}$ increases the central bank's uncertainty. 
Finally, it is worth noting that the forecasting rule for the central bank will change if it moves from a nondisclosure regime to a disclosure regime. Since $\theta_{t}$ follows a random walk, the linear estimates given by equations 26 and 32 are also forecasts of all future values of $\theta$. Needless to say, if the central bank continues to use the old (nondisclosure) forecasting rule under the new (disclosure) regime, its forecast will be off the mark. One could view this as a variation of the Lucas critique as applied to central bank transparency. The time-series properties of aggregate actions will change as the disclosure regime changes.

\section{Welfare Effects of Transparency}

The impaired signal value for the transparent central bank will impinge on any control problem that it faces, and it poses greater challenges in making decisions under uncertainty. Thus the central bank will face a trade-off between the welfare gains that result from being able to steer the future beliefs of economic agents, and the impaired signal value that results from disclosure of its forecasts. Evaluating the terms of such a trade-off is an important topic for future investigation. Furthermore, the degree of transparency itself emerges as one dimension of the optimal control problem: one can expect to see a future debate on "optimal transparency." We believe these issues to be the key to resolving the welfare effects of transparency in the spirit of the Hayek-Lange debate.

The debate to date, however, has concentrated on the one-shot model of beauty contests sketched earlier, where $\alpha$ is taken as given. Although the current debate sheds no light on the endogenous nature of central bank information, it is nevertheless illuminating in outlining some of the other dimensions of the debate.

\section{Welfare Effects in the Static Analysis}

Recall that, under the equilibrium decision rule (equation 12), the average action of individuals was equal to

$$
\frac{\alpha y+\beta(1-r) \theta}{\alpha+\beta(1-r)}
$$


Expressed in terms of basic random variables $\theta$ and $\eta$, we have

$$
\bar{a}=\theta+\frac{\alpha \eta}{\alpha+\beta(1-r)} .
$$

Thus increases in $\alpha$ and increases in $r$ unambiguously reduce the informativeness of the average action as a signal of $\theta$. In particular, public information always reduces the informativeness of average actions, even if $r=$ 0 , but strategic complementarities exacerbate the effect. Although we have not formally modeled the social value of information about $\theta$, we have focused on the importance of the information aggregation role of prices in private investment decisions and in the forecasting of the central bank. The welfare losses come not from coordination itself, but rather from the externalities imposed by the agents playing the beauty contest on those other agents who rely on prices to be informationally efficient. There is a market failure in which agents fail to internalize the externalities flowing from uninformative prices.

Some recent debates on the social value of information have focused on the welfare of the coordinating players themselves (rather than their external effect on others learning from their actions). In a previous paper we assumed that the beauty contest element of the individuals' decision is socially wasteful, entering only as a zero-sum component in payoffs, so that social welfare depends only on the variation of individual actions around $\theta .{ }^{41}$ In this case social welfare is enhanced only to the extent that individuals' actions approximate the fundamental state $\theta$. In such a formulation, increased precision of public information is not guaranteed to raise welfare. Expected welfare in that paper is given by

$$
\begin{aligned}
& E[W \mid \theta]= \frac{\alpha^{2} E\left(\eta^{2}\right)+\beta^{2}(1-r)^{2}\left[E\left(\epsilon_{i}^{2}\right)\right]}{[\alpha+\beta(1-r)]^{2}} \\
&=-\frac{\alpha+\beta(1-r)^{2}}{[\alpha+\beta(1-r)]^{2}}, \text { since } \operatorname{Var}(\eta)=E\left(\eta^{2}\right)=\frac{1}{\alpha} \\
& \text { and } \operatorname{Var}\left(\epsilon_{i}\right)=E\left(\epsilon_{i}^{2}\right)=\frac{1}{\beta} .
\end{aligned}
$$

41. Morris and Shin (2002). 
Welfare is increasing in the precision of the private signals, as we can see by differentiating equation 36 with respect to $\beta$ :

$$
\frac{\partial E(W \mid \theta)}{\partial \beta}=\frac{(1-r)\left[(1+r) \alpha+(1-r)^{2} \beta\right]}{[\alpha+\beta(1-r)]^{3}}>0 .
$$

However, the derivative of equation 36 with respect to $\alpha$ is

$$
\frac{\partial E(W \mid \theta)}{\partial \alpha}=\frac{\alpha-(2 r-1)(1-r) \beta}{[\alpha+\beta(1-r)]^{3}},
$$

so that

(39) $\frac{\partial E(W \mid \theta)}{\partial \alpha} \leq 0$ if and only if $r \geq \frac{1}{2}$ and $\frac{\beta}{\alpha} \geq \frac{1}{(2 r-1)(1-r)}$.

When $r>0.5$, there are ranges of the parameters where increased precision of public information is detrimental to welfare.

If $\alpha$ is restricted to some interval $[0, \bar{\alpha}]$ for technical feasibility reasons, we can expect a corner solution to the optimization of $\alpha$, in which the social optimum entails either providing no public information at all (that is, setting $\alpha=0$ ) or providing the maximum feasible amount of public information (setting $\alpha=\bar{\alpha}$ ). The better informed is the private sector, the higher the hurdle rate of the precision of public information that would make it welfare enhancing.

However, the zero-sum nature of the coordination element in payoffs is crucial to our 2002 result. If instead the coordination itself has some social value, the ambiguous effect of $\alpha$ disappears. Woodford describes utility functions that give rise to the same linear decision rule (equation 2) but allow for a social value of coordinated action; ${ }^{42}$ in this case welfare is no longer given by equation 36 but rather by

$$
-\frac{\alpha+\beta\left(1-r^{2}\right)}{[\alpha+\beta(1-r)]^{2}} .
$$

Woodford points out that this function is globally increasing in $\alpha$, and so greater precision of public information cannot be harmful.

42. Woodford (2005, appendix A). 
In the same spirit, George-Marios Angeletos and Alessandro Pavan propose a microfounded model that incorporates coordination elements in the welfare function. ${ }^{43}$ The coordination element comes from an investment problem with positive spillover effects, and so an explicit coordination premium is built into the problem. In particular, the welfare effects are closely tied to the fact that better public information allows the agents to eliminate the inefficiencies associated with coordination failure.

The coordination element in Hellwig's analysis is more subtle. ${ }^{44}$ Hellwig presents a macroeconomic model with monopolistic competition based on the Dixit-Stiglitz aggregators for consumption and price. In particular, the average price for the economy as a whole is given by the index

$$
P_{t}=\left[\int_{0}^{1}\left(p_{t}^{i}\right)^{1-\theta} \mathrm{d} i\right]^{\frac{1}{1-\theta}},
$$

where $\theta>1$ is the elasticity of substitution between goods, and $p_{t}^{i}$ is the price charged by firm $i$ at date $t$. In effect, the average price is a generalized harmonic mean of prices. ${ }^{45}$ This has important consequences. Although profit is increasing in $P_{t}$, it is decreasing in price dispersion, reflecting the fact that the harmonic mean always lies below the arithmetic mean. Thus a firm's expected profit increases when price dispersion is reduced. In turn, the form of the price index reflects the preference for variety implicit in the Dixit-Stiglitz utility function. For other specifications of preferences, an alternative perspective is to note that a consumer's indirect utility (utility as a function of prices at the optimum) is a convex function of prices, reflecting the ability of consumers to switch away from expensive goods in favor of cheaper ones. Price dispersion then has a beneficial effect. It would be desirable to understand more generally how welfare effects in Hellwig's model depend on attitudes to price dispersion.

Our original results are thus sensitive to the microfoundation given to the coordination motive. We highlighted this sensitivity in the online appendix to our 2002 paper. ${ }^{46} \mathrm{~A}$ recent paper by Angeletos and Pavan provides a

43. Angeletos and Pavan (2004).

44. Hellwig (2004).

45. More accurately, it is the power mean with a negative power. See, for instance, mathworld.wolfram.com/HarmonicMean.html.

46. Morris and Shin (2002); the online appendix is at www.e-aer.org/data/dec02_app_ morris.pdf. 
unified analysis of the value of public information strategic problems with quadratic payoff..$^{47}$ Their analysis makes use of a comparison of equilibrium behavior with an "efficient" outcome, corresponding to a constrained planner's problem, where the planner can mandate players' actions as a function of their signals but cannot observe the signals. Their analysis highlights that the results in our 2002 paper rely on both the lack of externalities in payoffs and that the equilibrium involves an inefficiently high level of coordination. Thus continuing work on the welfare analysis of public information with a microfounded coordination motive is clearly valuable. However, we have emphasized elsewhere in this paper that the dynamic effects of information revelation may be important and that one should not rely too heavily on the one-shot version of the beauty contest model in drawing conclusions about the desirability of greater transparency.

\section{Relative Precision}

In a reply to our 2002 paper, Lars Svensson raises another issue..$^{48}$ Taking our payoffs at face value, he makes two observations. First, the result that welfare is locally decreasing in the precision of public information holds only with restrictions on the information parameters that are empirically very restrictive ( $\alpha$ has to be small relative to $\beta$ ). Second, even on a global analysis, when the precision of the public signal is no lower than that of the private signal, welfare is higher with the public signal than without it.

Svensson's point can be explained by referring back to welfare as given by equation 36, but expressed as a function of $\alpha$. Let us denote this by $V(\alpha)$. Thus,

$$
V(\alpha)=-\frac{\alpha+\beta(1-r)^{2}}{[\alpha+\beta(1-r)]^{2}} .
$$

On the assumption that withholding the public signal is equivalent to setting $\alpha=0$, the ex ante welfare in the absence of the public signal is thus

$$
V(0)=-\frac{1}{\beta}
$$

47. Angeletos and Pavan (2005).

48. Svensson (forthcoming). 
There is a hurdle rate $\bar{\alpha}$ for the precision of the public signal such that welfare with the public signal is lower than welfare without it if and only if $\alpha<\bar{\alpha}$. The hurdle rate is the value of $\alpha$ that solves $V(\alpha)=V(0)$ and is given by

$$
\bar{\alpha}=\beta(2 r-1) .
$$

Since $0<r<1$, the hurdle rate is lower than the precision $\beta$ of the private information. Thus, for the benchmark case where the precision of public information is no lower than that of private information (that is, where $\alpha \geq \beta$ ), welfare is higher with the public signal than without it.

Without taking fully into account the endogenous nature of $\alpha$, it would be difficult to come to a firm conclusion on the relative sizes of $\alpha$ and $\beta$. We can see from figure 3 above that, when good public information depends on a high precision of private information, choosing one has implications for the other.

The evidence from Romer and Romer that the Federal Reserve's Greenbook forecasts outperform the forecasts of the Federal Reserve's private sector counterparts is often cited as evidence that $\alpha$ is greater than $\beta .^{49}$ However, private sector forecasters are not the typical "economic agent" studied in most economic models. Rather they are special types of agents who try to mimic the central bank's decision problem, but with fewer resources. Thus $\beta$ should be understood to refer to the information precision of genuine economic agents who learn about the current state of the economy from their own transactions. For instance, in the price setting game version of the beauty contest rule, each economic agent is a firm trying to balance the competitive effects of price changes with the need to keep price above marginal cost. Here $\beta$ is the precision of the firm's estimate of its own marginal cost. The stylized model in our 2002 paper also suffers from the fact that it imposes independence of the signals conditional on $\theta$. The online appendix to that paper dealt with a more general case that allows for correlated signals, and Morris, Shin, and Hui Tong present an example, in a reply to Svensson,,$^{50}$ showing the variety of welfare effects that may arise away from the simple benchmark case, and in particular that public information may be damaging even at high levels of public precision.

49. Romer and Romer (2000).

50. Morris, Shin, and Tong (forthcoming). 
The debates formulated in the static model have extended our understanding along several dimensions, but the limited nature of the static framework and the sensitivity of the results to the assumed payoffs suggest that we have come close to the limits of useful debate within the confines of such a restrictive framework. Much more important would be the endogenous nature of public information precision itself. It is this issue that lies at the heart of the debate between Hayek and his socialist contemporaries, and the largest stakes in the monetary policy transparency debate lie here.

\section{Implications for Monetary Policy}

One of the pitfalls of engaging in any debate is that of overselling one's case and making possibly untenable claims. The dangers are large, especially if the issue is something as basic and desirable as the transparency of a prominent and influential public institution. Thus it is worth taking a deep breath and a larger perspective. The arguments presented in this paper do not address the question of whether any particular forecast or other information should or should not be disclosed. Rather, the objective has been to review arguments about the trade-offs involved in the choice of framework for communicating with diverse economic actors. Nor do we claim that transparency (or inflation targeting, or publication of forecasts) is undesirable. Our aim is the much more modest one of drawing attention to the two-sided nature of the debate.

Transparency affords considerable leverage to central bankers in influencing the beliefs of economic agents. But this in turn may reduce the signal value of private sector actions. The Bank of England's recent experience provides a glimpse into the difficulties faced by a central bank when it has poor information on the current state of the economy. At its August 2005 meeting the Monetary Policy Committee voted by a majority of five to four to lower the policy rate. The minutes of the meeting represent the views of the members who voted against the cut as follows:

For these members, there appeared to be little risk in waiting for further data. Given the difficulty in explaining a reversal of a decision soon after a turning point, should that prove necessary in the light of future data, it was advisable to accumulate a little more evidence than usual before changing interest rates. ${ }^{51}$

51. www.bankofengland.co.uk/publications/minutes/mpc/pdf/2005/index.htm, p. 9 . 
The uncertainty about the current state of the economy clearly played on the minds of all members. Uncertainty as to where the economy actually was at the time was also a prominent theme at the press conference following the publication of the August 2005 Inflation Report. ${ }^{52}$

To the extent that uncertainty about current conditions makes forecasting more difficult, another telltale sign of a drop in signal values would be a deterioration in forecasting performance. Of course, such a deterioration cannot be seen as a clinching argument for a drop in signal values (there may be other culprits), but we have seen that changes in the disclosure regime are associated with changes in the time-series properties of aggregate outcomes, as well as changes in the signal value of those outcomes. When poor signal values conspire with structural change in the economy, forecasting will be extremely difficult. Thus forecasting failures would certainly be consistent with a drop in signal values. There is some recent evidence of a deterioration in the forecasting accuracy of central banks and their private sector counterparts. ${ }^{53}$

At the Federal Reserve, the staff of the Board of Governors prepares a detailed forecast before each scheduled meeting of the Federal Open Market Committee (FOMC). The purpose of this forecast, known as the Greenbook, is to serve as background to the deliberations in the FOMC, and the views expressed are those of the staff rather than individual committee members. Sims provides a detailed description of the process by which the Greenbook forecasts are arrived at. ${ }^{54}$ The forecasts are posted on the website of the Federal Reserve Bank of Philadelphia, except for the most recent five-year window, which remains confidential. Peter Tulip's study therefore uses the publicly disclosed data that include forecasts of outcomes up to the end of 2001.55

Tulip finds that, even as output fluctuations have moderated substantially in recent years, ${ }^{56}$ forecast errors have not. The fact that policy responses are endogenous and that output fluctuations have moderated both make

52. A video of the press conference is available at the Bank of England website, www.bankofengland.co.uk.

53. The evidence is documented in Schuh (2001) and Campbell (2004) for private sector forecasters, and in Goodhart (2004) and Tulip (2005) for the Bank of England and the Federal Reserve, respectively.

54. Sims (2002).

55. Tulip (2005).

56. The moderation in output fluctuations has been documented by McConnell and Perez-Quiros (2000), Kim and Nelson (1999), and Blanchard and Simon (2001). 
forecasting more difficult. Nevertheless, it is notable from Tulip's study that the performance of longer-term forecasts for output (up to eight quarters) has not been encouraging. Since the late 1980s, mean squared prediction errors have been similar to, and sometimes greater than, the variance itself. In other words, the simple sample mean (the most naïve forecast) has proved a more accurate guide to GDP growth than the actual forecasts, which is to say that the forecasts have had negative predictive value.

One way to picture this is to consider a regression of the two-year change in GDP on a constant and the corresponding forecast. This regression has a negative coefficient when estimated on the last ten years of the sample (1992 to 2001). C. Goodhart reports findings for the Bank of England's forecast performance, which demonstrate a similar lack of predictive power for longer-term forecasts, but Goodhart points out that, when the central bank acts on the forecasts themselves, the lack of correlation between the initial forecast and the final outcome should be expected. ${ }^{57}$ Sean Campbell reports results from private sector forecasts and finds that short-term forecasts of the Survey of Professional Forecasters have a negative $R$-squared over the period 1984-2003, echoing Tulip's result for the Federal Reserve. ${ }^{58}$

If the central bank does not recognize that signal values are impaired in a world of managed expectations, it may be lulled into a false sense of security when in fact imbalances are building in the economy. Even though consumer goods prices may be stable and the flows in the IS curve are well behaved, asset prices may be buoyed by excessively lax credit conditions, building up problems for the future despite no obvious signs of trouble.

If inflation targeting is practiced flexibly, the output costs of financial distress could figure in the overall calculations. Less easy to overcome would be the political economy hurdles facing a central bank's monetary policy committee whose mandate is interpreted narrowly as inflation and output stabilization over a relatively short horizon. The key issue is whether a monetary policy committee that suspects that imbalances are building up under the radar feels that it can justify departing from the inflation target over the targeting horizon in order to forestall larger problems over a longer horizon.

57. Goodhart (2004).

58. Campbell (2004). 
Australia provides one recent instance where a central bank has acted to lean against the wind, raising interest rates and then keeping them high in the face of an overheating residential property market, even though consumer prices and output were well behaved. The Reserve Bank of Australia (RBA) came under considerable criticism for acting beyond its mandate: critics claimed that it was looking "beyond its horizon" of two years in targeting inflation. By taking such actions, the RBA was undoubtedly risking its own reputation, since the politically more expedient path would have been to stick to a more narrow interpretation of its mandate. In the event, the RBA's preemptive actions proved well advised, and its reputation has been enhanced. Thus, in practice, central bankers have adapted well to the new inflation targeting regime, and debates are frequently conducted in broader terms.

It is beyond the scope of this paper to broach the larger topic of central bank accountability. Transparency in this broader sense is crucial for establishing and maintaining the political legitimacy of the central bank as a public institution. ${ }^{59}$ But there is a potential paradox of transparency. One of the inevitable fruits of the success in influencing beliefs is that the central bank has to rely on less informative signals to guide its decisions. If policymakers are to consolidate the successes achieved to date, they will have to turn their attention to how monetary policy should be conducted in an era when prices are less informative.

59. Geraats (2002) gives a taxonomy of the different types of transparency. 


\section{Comments and Discussion}

Benjamin M. Friedman: A firm belief in the miraculous healing power of central bank transparency is a core tenet of the new religion that the economics of monetary policy has somehow become. In the rush to dissociate themselves from the long-standing practices of their predecessors (and, one sometimes suspects, to avoid talking about their actual policy decisions), central bankers today tirelessly repeat the mantra that open communication with the public is fundamental to carrying out their assigned task. Economists reiterate the same conviction, albeit with little or no more analytical grounding to indicate just why, or how, enhanced transparency delivers the wonders claimed for it.

Stephen Morris and Hyun Song Shin, in an interesting series of papers, have ventured the heresy that perhaps, under some conceivable circumstances, less transparency might be better than more. The question is plainly worth consideration. But wholly apart from whatever answer they may provide to the question of how much transparency is "just right," the potential value of Morris and Shin's work lies in the effort to spell out how central bank transparency matters in the first place. That alone would constitute a significant contribution to the discussion.

Morris and Shin nicely situate their inquiry within the broader setting of economic theory by appealing to the debate, which they personify in Hayek and Lange, over the informative value of prices. To understand how the beneficial value of central bank transparency has come to be such a core belief of current-day monetary economics, however, I think it is also useful to situate this subject in the context of the still broader debate over the social optimality of unfettered private market behavior. 
Monetary policy has always presented something of a challenge in this regard. Even such dedicated free-market advocates as Milton Friedman have strongly defended the central bank's role as a necessary deus ex machina, exogenously fixing some economic magnitude (for Milton Friedman it was the money stock; today we more typically think of a short-term interest rate, although this is problematic in yet other ways) so as to anchor the nominal price level. The nominal price level is not a matter of economic significance, but rather a convention: a social artifact. Hence private markets require some outside agent to establish its basis. Since the provision of a monetary standard (itself a social artifact) is traditionally a well-recognized responsibility of the state, the role of anchoring the system of nominal prices inherent in a monetary economy likewise falls to the state, or more typically to one of its constituent agencies.

The resulting tension between belief in the social optimality of unfettered private market outcomes and the required reliance on a government agency is an underlying theme that pervades the writings not only of Milton Friedman but of countless others in this vein as well. Much of the literature dealing with monetary policy consists of pointing out how poor decisions on the part of the government, in this case the central bank, have brought about this slump, or that inflation, or whatever other economic misfortune might have occurred. The source of the tension is that the standard laissez-faire remedy-simply have the government go out of business-is unavailable in this setting because of the need to establish the nominal price level. Apart from advocates of free banking, who have always remained on the fringe of the subject, the normal form of analysis in this field therefore consists of comparing actual central bank practice against some designated alternative.

Today's focus on central bank transparency is a further dimension of the ongoing effort to attribute whatever plainly nonoptimal economic outcomes occur to government action, rather than to any failure of optimality on the part of private market activity. In this case it is private actions that are nonoptimal, not government actions, but the argument is that it is the government that leads private economic agents to make mistakes. This avenue for finding the government at fault is especially appealing within the new approach to thinking about monetary policy according to which central banks never $d o$ anything anyway-at least not anything that matters. Instead, only what the central bank says-the 
"management of expectations"-is important. This paper by Morris and Shin lies squarely within this particular line of literature. As I shall argue, however, while the "management of expectations" orientation provides the setting for Morris and Shin's analysis, it also sharply limits what that analysis can accomplish.

The crucial issue, as Morris and Shin portray it, is monetary policymakers' need to learn about the state of the economy. They do so by observing market prices set by private economic agents acting atomistically in markets. But those agents' actions in turn depend on what the central bank tells them, and hence so too do the prices that they collectively establish. As a result, it is at least conceivable-and the burden of Morris and Shin's analysis is to show how this can happen-for the central bank to weaken the information value of the prices that policymakers observe by disclosing too much about what the policymakers themselves think. In other words, it is possible to be too transparent.

Although the formal optimizing model on which the private agents rely is merely sketched out, the intuition behind this result is clear enough. Each private market participant has access to two sources of information about whatever matters in the economy: what he or she sees individually, and the publicly available statements of the central bank. The right inference to draw is some appropriately weighted combination of the two. But the more weight private agents place on what the central bank says in forming their expectations and acting accordingly, the less information is conveyed to policymakers by the prices that these agents' actions collectively determine. In the limit, market-determined prices completely lose their function as an aggregator of the disparate information that private market participants individually observe.

The conception of a market that Morris and Shin deploy for purposes of this analysis is Keynes's famous "beauty contest," in which, importantly, nothing of objective significance is involved. Each participant simply tries to guess which contestant (or, in the analogy Keynes had in mind, which company's stock) will be judged most attractive by the greatest number of other participants. As Morris and Shin explain, such a mechanism is subject to multiple equilibria, and it is easy to see how some deus ex machina could influence at which equilibrium the market will settle. But, to repeat, the greater is the influence that the deus ex machina exerts, the less the resulting equilibrium reveals about any underlying preferences or information the participants actually have. 
To see the limitations of this line of analysis - and to understand why it emerges so readily from the "management of expectations" view of monetary policy-consider an alternative conception of a market: a "real estate" model. Instead of judging which is the prettiest face, participants now attempt to guess which parcels of a town's real estate are most likely to be developed in a way that will enhance their economic value. And in place of a central bank that doesn't $d o$ anything, but merely says what it thinks, the deus ex machina is now a well-financed developer who, with some probability, will purchase and develop one or more of the relevant parcels. Here, again, whatever information and preferences private participants bring to the market are potentially of value. The market is again subject to multiple equilibria. Whatever view is expressed by the deus ex machina can again influence the market to settle at one equilibrium rather than another. But now this influence follows from the probability that the deus ex machina - the developer-will take an action that objectively matters for the outcome.

In the world of monetary policymaking, a central bank's statements about the future are subject to a certain tension that the difference between these two models illustrates, regardless of whether such statements are issued publicly or are merely part of the central bank's internal deliberations: Is what is being said a prediction of what policymakers think will happen? Or is it an expression of policymakers' preferences about what should happen? Indeed, is there any distinction between the two?

When policy actions affect outcomes with a delay, as monetary policy actions do, the answer is trivial for horizons shorter than the operative lag. Any such statements are obviously predictions. But, for longer horizons over which policy actions could be influential, why would a policymaker predict an outcome other than what he or she prefers (conditioned, of course, on all relevant constraints and externally driven factors)? To put the question the other way around, if the policymaker saw a particular outcome as the likely consequence of one sequence of policy actions, but preferred a different outcome also within the feasible set, why would he or she not switch to a new sequence of actions in order to achieve it? Such a line of questioning lies outside the Morris-Shin analysis because the "beauty contest" model on which they rely, in keeping with the "management of expectations" view of monetary policy, does not admit of central bank actions, as distinct from announcements, in the first place. It is telling that Morris and Shin see the entire point of the central bank's having better 
information as gaining "authority ... in the eyes of [economic] agents." The concern they raise is that "Public pronouncements can thus crowd out private opinions." But when the central bank indicates what it will in fact do, and when the actions it is going to take will shape the relevant economic outcomes, its public pronouncements about the part of the economic future that it will thereby affect should "crowd out private opinions."

Shifting the ground of the analysis to this broader conception of monetary policy, in which the central bank does have the ability to take actions that matter for the economy, in no way makes the question Morris and Shin are addressing disappear. For example, if the central bank's sole objective were to keep inflation as close as possible to 2 percent a year, and market participants had confidence both in the central bank's commitment to this monocular objective and in its ability to achieve it (at least on average over time), then at least one element of private sector expectationswhat do people expect the medium- to long-run inflation rate to be?-is no longer available to inform policymakers' decisionmaking.

But stating the problem in this way places a different, and more familiar, cast on the matter. A fundamental economic principle, familiar in the economics of monetary policy and elsewhere, is that one cannot control both price and quantity in a market that clears. In the 1970s and 1980s, when many central banks debated whether to formulate and implement monetary policy in terms of interest rates or money growth, a standard feature of that discussion was the realization that whichever one the central bank chose would then be unavailable as an informative signal: policymakers obviously cannot learn anything from observing the level of an interest rate that they have set themselves, nor (subject to complications associated with imperfect control mechanisms) can they do so from observing movements of the money stock that they have themselves chosen. Correspondingly, if the central bank solely targets inflation, and does so credibly, it of course renders medium- and long-term inflation expectations uninformative. The same would be true for the output gap if a central bank could credibly target output some small but safe distance below the (presumably varying) full-employment level.

To be sure, one could reintroduce the Morris-Shin line of inquiry into this kind of thinking as well: What if the central bank targeted inflation, and credibly had the ability to make good on its objective, but refused to announce its target? Yes, the public's medium- and long-run inflation expectations would then not just mirror back the central bank's own target. 
But presumably they would have far more to do with private agents' guesses about the undisclosed target than with anything concerning what they know - and what policymakers would like to learn from them-about underlying economic conditions. Although there may well be a case to be made for limiting the transparency of the monetary policy process, I suspect it is unlikely to revolve around any supposed benefits to be had from concealing policymakers' intentions for the central trajectory of policy or the economy.

(What might be an example of a case for limited transparency? The one that comes most immediately to mind involves contingency planning. What if the central bank fears, but does not see as highly likely, some adverse outcome and discusses in advance what actions it would take should the problem materialize? Would learning about these contingency plans reassure market participants that any such problem would be adequately met? Or would the mere fact that the discussion had taken placethat policymakers saw the problem as sufficiently likely to warrant talking about it—be unsettling?)

My reading of the recent discussion of central bank transparency, including not only the nascent academic literature but also the profusion of pious utterances on the subject by practicing central bankers, is that the whole subject matters far less than either casual or attentive readers and listeners are led to believe. The case for limiting transparency, as argued by Morris and Shin, is not persuasive at any practical level. Indeed, the closest they come to saying something about the actual conduct of monetary policy—raising the admittedly hard question of whether policymakers should respond to potentially destabilizing movements of asset prices even when both goods-and-services inflation and real output are behaving as expected and desired - actually has nothing to do with the analysis in their paper. But the repeated claims by others of the practical benefits of transparency are not persuasive either. For the most part, they are either efforts by academic economists to show that socially undesired outcomes cannot be the fault of private market activity, or attempts by central bankers to change the topic of conversation.

Let me conclude by addressing two aspects of the broader policy debate that constitutes the setting of Morris and Shin's paper: specifically, whether the Federal Reserve System, the European Central Bank, the Bank of Japan, and other central banks that have not adopted some form of explicit inflation targeting for the conduct of their monetary policy should 
follow the increasing number of central banks that have already done so. First, the economic benefits recorded to date by existing inflation-targeting regimes are, at best, still at issue. For example, inflation in the United States in recent years has been low and stable, and output fluctuations have been relatively muted. Yet the Federal Reserve has not been targeting inflation, at least not in any way that involves public announcements of the kind that Morris and Shin (following the rest of the literature) emphasize. Indeed, the Federal Reserve has resisted numerous calls to adopt an explicit inflation-targeting framework; that is precisely what the debate is about.

What then accounts for the favorable performance of U.S. inflation and output? And how does one know that whatever has delivered these benefits in the United States has not also done so elsewhere, including in countries where the central bank has adopted inflation targeting? Numerous empirical researchers have investigated just these questions, but the results have been mixed. For example, the paper by Ball and Sheridan that Morris and Shin cite concludes that "Once one controls for regression to the mean, there is no evidence that inflation targeting improves performance ... as measured by the behavior of inflation, output, and interest rates."

Second, as Morris and Shin make clear, a major theme in the debate over inflation targeting is the desirability of monetary policy transparency. Much of the discussion of this subject proceeds from the assumption that inflation-targeting regimes are more transparent than other ways of conducting monetary policy. I believe this assumption is false, however, at least in regard to how inflation targeting is actually practiced today (and this is, as well, the object of Morris and Shin's interest).

The issue here is multiple policy objectives. As is well known-and as Lars Svensson's work in particular makes clear-inflation targeting does not imply that the rate of inflation is necessarily, or even probably, the sole objective of monetary policy. But how can a central bank that also has preferences with regard to output or employment, or the economy's international balance, or any of the variety of other aspects of economic activity with which a central bank may plausibly be concerned, go about being transparent about the objectives it is pursuing in its monetary policy?

One thing it could do-and that Svensson has repeatedly proposed-is to be explicit about its policy framework by stating publicly its objectives as well as the constraints it sees itself facing as it pursues those objectives. But few central banks that practice inflation targeting do this. Instead inflation targeting is more often a procedure under which the central bank, 
while perhaps willing to acknowledge objectives other than the rate of inflation if pressed very hard to do so, normally goes to great lengths to conceal any objectives other than inflation-for example, by titling its public reports on monetary policy "inflation reports," as if inflation were the only aspect of the economy that mattered for policy purposes, or by issuing public statements that typically make no mention of any tension, at any horizon, between the bank's inflation goal and its other economic aims. The resulting "transparency" is like that of polarized glass: one dimension of what the central bank is doing is fully transparent, or at least as transparent as one dimension of a multiobjective optimization problem can be when treated in isolation, while the other is fully opaque.

The reason for raising this familiar issue here is that the distinction between what the central bank is and is not transparent about is relevant to Morris and Shin's interpretation of other researchers' empirical findings as they bear on the more central aims of this paper. Morris and Shin point to the erosion of forecasting accuracy that some researchers have reported for recent years, in one country or another, as evidence that when the central bank tells market participants what to think about the future, those participants put less effort into processing the other information at their disposal. An alternative interpretation is that when the central bank discloses its objectives for inflation but conceals its objectives for real economic outcomes - indeed, pretends that those other objectives do not exist-it is hardly surprising that real outcomes become harder to predict. Either way, it is important not to claim for any policymaking regime, even inflation targeting, virtues that it does not possess.

Christopher A. Sims: The economics of information has provided many examples of models that display conflicting and paradoxical results. This reflects the fact that information does not fit well within the usual paradigm of economic analysis, namely, a world populated by constantly optimizing, completely rational agents whose actions are guided by market prices. Information, although in some sense marketed, is not an ordinary commodity. Although it can be costly to acquire, it can be disseminated at zero social cost. Although valuable, it is difficult to sell, because it so easily becomes available to people who have not paid for it yet can observe the actions of people who have. There are many reasons, therefore, to think that markets cannot be expected to guide the acquisition and dissemination of information in an optimal manner. 
A standard argument is that information will tend to be underproduced, because of the difficulty of appropriating its value once it is produced. Jack Hirshleifer, in a classic paper, ${ }^{1}$ showed that, because information acquired earlier than others acquire it may have a private value that exceeds its social value, it may instead be overproduced in equilibrium. A standard idea, going back at least to the article by Hayek that this paper cites, is that markets are efficient aggregators and transmitters of information. The article by Sanford Grossman that they also cite shows that the public signal that market prices provide destroys the incentive for agents to expend resources acquiring information. ${ }^{2}$ Efficient allocation therefore in general requires frictions that imply that prices do not perfectly aggregate information and that information flows by routes other than only through prices.

This paper by Stephen Morris and Hyun Song Shin explains an interesting paradox in information economics that has received attention in the recent literature, starting with the authors' own seminal work in the area. Public provision of information that is of higher quality than that produced by any private agent can reduce the efficiency of allocation by reducing the incentive for agents to act on their own information and thereby reducing the informativeness of prices. My view is that this paradox is well worth understanding and keeping in mind when evaluating government programs devoted to information gathering and dissemination. In this context it has to stand beside a number of other paradoxes and difficulties that make the straightforward cost-benefit accounting approach to evaluating government data dissemination programs inapplicable. ${ }^{3}$

But, although this paper and the formal models it contains are best thought of as applying to government programs to disseminate data, the paper's title and much of its informal discussion suggest that its ideas apply to monetary policy, and to inflation targeting in particular. This seems to me quite far-fetched. It reflects a failure to make an important distinction between, on the one hand, dissemination of information about policy actions that the government cannot avoid taking, and, on the other hand, dissemination by the government of information about the state of the private economy.

A central bank can make choices about which nominal value it wants to control-it can be an aggregate price index, an exchange rate, a monetary

1. Hirshleifer (1971).

2. Grossman (1976).

3. Committee on National Statistics (1985, chapter III). 
aggregate, or Alan Greenspan's current judgment of the level of inflationary pressure. But there is no laissez-faire option here. A central bank is not a planning board that can either set prices by computer, substituting for the market, or let the market do it. It is a government agency that must take some actions that are relevant to private decisions, and either it can try to dispel uncertainty about what actions it has taken and will take, or it can maintain public uncertainty about its operations and policies. It is true that, in the course of explaining how it chooses the actions that it must take, it may provide information about its own evaluation of other sources of uncertainty, unless it acts without looking at these sources of uncertainty. Morris and Shin are suggesting that this release of information may be so important and deleterious a side effect of central bank openness as to justify maintaining secrecy about the central bank's policy actions.

Morris and Shin write about central bank transparency reducing the "signal value of prices." This is misleading language. Any policy that succeeds in making fluctuations in the price level small will almost inevitably reduce the "signal value" of the average price level. The macroeconomics literature is full of models in which this is a highly desirable outcome, because only relative prices - not the price level - matter for allocation, and eliminating uncertainty about the course of the price level increases both the precision of private estimates of relative prices and the incentives for private agents to accumulate information about local prices and conditions.

THE LUCAS-PHELPS MODEL. The only model laid out in the paper that has a central bank determining a numeraire price is the Lucas-Phelps islands model. It is true that that model has the structure of the publicprivate information games that Morris and Shin discuss. But since the monetary authority determines the price level in that model, there is, as they acknowledge, a simple prescription for optimal policy: the central bank should announce what it is doing. It thereby provides perfect public information, which is always optimal in these setups.

The Lucas-Phelps model turned out to represent a short branch on the tree of subsequent research, precisely because it generated real effects of monetary policy only by assuming that agents could not observe directly what the monetary authority was doing. As soon as one introduces agents who can read about the money stock every week, or the federal funds rate every day, all real effects of monetary policy disappear in that model. Recently there has been interest in rational inattention models, in which agents, because of limited capacity to process information, do not make 
optimal use of all available information, even when it is free. In such a framework, something like a Lucas-Phelps model can emerge. However, in such a framework the abstraction, common to all the work that has built on the Morris and Shin framework, that there is a fixed "private information" cost schedule, does not make sense. In fact, because any effort that capacity-limited agents expend on trying to extract information about imperfectly observed randomness in monetary policy is effort that cannot be devoted to evaluating the state of local markets, the case for transparency is likely to be stronger in a rational inattention framework.

Some have integrated the Morris-Shin public-private information setup into standard "micro-founded" macroeconomic models. The authors mention most of these models, but it perhaps bears more emphasis that, in all of these setups, increased public information turns out to be welfare improving.

INFLATION TARGETING. Inflation targeting as it is actually practiced amounts to the central bank making projections roughly two years ahead of the likely path of inflation and, in most cases, output growth. These projections are published two to four times a year, in a document that explains the central bank's view of the current state of the economy and of the reasoning behind at least its current policy actions. (Two central banks, in New Zealand and Norway, also display and discuss estimates of future settings of the policy rate.) Inflation targeting represents an attempt to credibly establish that the central bank is committed to maintaining price stability. It has several advantages over previously proposed commitment devices, such as constant money growth, exchange rate targets, or algebraic formulas ("rules") connecting current policy actions to observed variables. One advantage is that it is believable that the central bank, and the government more generally, care directly about inflation. Thus, if unforeseen events force a deviation from the inflation target, a central bank announcement that this was unintentional, accompanied by a plan of action for returning to the target, is more believable than such an announcement would be if the target were, say, money growth. Inflation may still turn out high and output growth low, encouraging doubt about the strength of the central bank commitment. But this will be far less severe than the doubts that must arise about commitment to a money growth target if money growth is high, while both inflation and output growth are low.

Advocates of inflation targeting hope and expect that it will result in expectations of future inflation remaining close to the target level, even when there are short-run deviations from target. There is some evidence 
that this is in fact the case, and Morris and Shin cite some of that evidence. If private sector inflation expectations were thus anchored, while actual inflation deviated sharply from those expectations, there might be concern that private sector forecasts were deteriorating in quality because of too great a focus on the announced targets. This does not seem to be what is happening in inflation-targeting countries, however. The private sector is accurately anticipating that inflation will remain stable. The fact that this seems to be happening is, of course, not evidence of any deleterious effects whatsoever on private sector forecasts or estimates of the current state of the economy.

"OVERREACTIONS." The bond markets are very interested in what the Federal Reserve is going to do with interest rates. In periods when the Federal Reserve has announced that it is trying to control a monetary aggregate, therefore, news about the values of those aggregates has a big effect on bond markets. This has no implications at all, however, for whether there are externalities of the type that Morris and Shin need for their story. They refer to this pattern as an overreaction of bond markets, but they give no evidence that this is anything more than markets correctly incorporating new information about the likely path of monetary policy. Monetary targeting does indeed create uncertainty about interest rates, because of the volatility of money demand, and this is reflected in bond markets being less stable under such a regime. This is one of the arguments for why inflation targeting is an improvement on monetary targeting. So this is another piece of anecdotal evidence that in fact adds no weight at all to the authors' case against central bank transparency.

EVIDENCE FROM DATA REVISIONS. The particular shape of the fan charts that the authors reproduce from the Bank of England inflation reports is no doubt related to uncertainty connected to data revisions. The August report itself has a discussion of data revisions, pointing out that they are related to the difficulty of getting accurate current estimates of service sector output. The Bank of England uses survey data as a check on the preliminary data it receives, and in August 2005 it argued that there was an unusually large discrepancy between the survey-based estimates and the preliminary data. Probably the square-shouldered shape of the August fan chart reflects this analysis. There is no indication in the Bank's own discussion that data revisions are getting larger, except possibly for a trend toward a larger service component in output.

CHANGES IN FORECAST ACCURACY. The paper cites several studies that are supposed to show a decline in forecast accuracy of central bank 
forecasts. The most recent of these, by Peter Tulip, ${ }^{4}$ cites the others, claims it is largely consistent with the others, and focuses specifically on changes in accuracy over time. Its conclusion is that forecast accuracy has improved significantly at horizons up to four quarters or so, that it has deteriorated noticeably for forecasts at an eight-quarter horizon, but that the deterioration at this long horizon is nowhere near statistically significant.

What is clear is that the overall variance of output growth has declined and that this decline has been concentrated in the predictable component of output growth. Note that this is exactly what would be expected from improved monetary policy if monetary policy can influence short-run fluctuations but cannot do much about the overall shape of business cycles or long-run growth. The conclusion must be that there is no reliable evidence of any decline in central bank forecast accuracy, that there is reliable evidence of improvement in short-run central bank forecast accuracy, and that the pattern of results provides no support for the notion that central bank forecasts become worse under inflation targeting.

THE PHILLIPS CURVE IS FLATTER. Natural rate theory (which is based loosely on the Lucas-Phelps model) implies that, when the inflation rate becomes more predictable, unemployment shifts will be mainly those arising from real shocks and hence not associated with a negatively sloped Phillips curve. One does not have to believe in a strict natural rate theory to see that the graphs in this paper seem roughly consistent with the story that uncertainty about monetary policy has declined, and with it the slope of the Phillips curve, as the natural rate theory suggests. Of course, if agents in the economy were trying to use the aggregate price level to measure an otherwise unobservable unemployment rate, this could have negative side effects. But the unemployment rate is, for the time being, published data.

ASSET PRICE BUBBLES. The authors' setup in this paper provides a clear description of how a public authority that announced projected time paths for real asset prices could cause distortions. For example, a central bank that announced that house prices were too high and published charts showing a decline in prices could, at least temporarily, produce an unjustified decline via the coordination on public information that the authors model. This is an argument against the central bank even making statements about house prices, much less taking policy actions based on its private assessment of the housing market.

4. Tulip (2005). 
But Morris and Shin instead seem to believe that inflation targeting and monetary policy transparency might lead to asset price bubbles. Why they think so is unclear, at least to me. Asset price bubbles have occurred repeatedly in history, under many monetary policy regimes. They are basically a real phenomenon, involving uncertainty about a novel investment technology and a division in the market between optimists and pessimists. The optimists borrow from the pessimists and thereby finance a runup in asset prices. Sometimes, but not always, the optimists turn out to be wrong. Or perhaps it is more accurate to say that the early optimists are generally right, the late optimists are generally wrong, and there is great ex ante uncertainty about the date separating the late ones from the early ones. But we lack a model of how transparent monetary policy and stable prices play into this process. It seems to me most likely that a general policy of having the central bank declare when "early" has become "late," and at that point contracting monetary policy, would increase the variability of the price level without any offsetting good effects. Of course, to the extent that asset prices affect wealth, and hence spending, and hence eventually prices, the central bank should take account of them.

The United States has recently had a stock price boom that ended without major disruption to the price level or output growth. In Australia, as the authors point out, an inflation-targeting bank weathered a house price boom well. The Reserve Bank of Australia did engage in contractionary policy during the house price boom, but it rationalized its contraction on the basis of its forecast of an acceleration in the inflation rate.

In November 2003 the Reserve Bank raised the policy rate by 1 percentage point and held it there through the beginning of 2005. As the following actual inflation figures show, it appears that the Reserve Bank anticipated correctly that inflation was on the rise:

Australia: quarterly change in the consumption deflator

Percent a year, annualized

$\begin{array}{rrrr}2002: 1 & 3.68 & 2004: 1 & 3.55 \\ 2002: 2 & 1.22 & 2004: 2 & 1.17 \\ 2002: 3 & 2.43 & 2004: 3 & 1.17 \\ 2002: 4 & 1.61 & 2004: 4 & 2.33 \\ 2003: 1 & 4.79 & 2005: 1 & 2.70 \\ 2003: 2 & -1.19 & & \\ 2003: 3 & 0.80 & & \\ 2003: 4 & 1.59 & & \end{array}$


The house price boom might have contributed to the Reserve Bank's estimate of inflation, but it does not appear that this was a case of raising interest rates to stop a house price boom when concerns about aggregate inflation did not justify raising rates.

IS THERE ANY DOWNSIDE TO INFLATION TARGETING? Morris and Shin do not present a convincing case against inflation targeting, based on worries about such targeting repressing private information gathering. It is worth mentioning, however, that there are other, stronger reasons to think that inflation targeting is not a universal cure for the ailments of monetary policy.

Inflation targeting is a good idea when the central bank can actually control inflation. If it cannot, then inflation targeting will either simply fail and undermine credibility, or temporarily succeed by misleading the public, thereby making things eventually worse. In many developing economies the fiscal policy that is essential backing for central bank control of the price level is in doubt, and in those circumstances it may be better for the central bank simply to forecast inflation and point out the extent to which its forecasts are contingent on fiscal policy.

In the United States and other advanced economies, it has for decades been the norm to assume away any problems with fiscal backing for monetary policy. Today, however, with a Congress and an executive branch that seem convinced that lower taxes are always better and have been discovering that, if spending opportunities entail no tax increase, many of those opportunities are politically attractive, the United States may now be conducting a natural experiment in the limits on central bank control over the price level. One should hope that they and the Federal Reserve do not embark on such an experiment and on inflation targeting at the same time.

General discussion: Alan Blinder remarked that the fundamental argument for central bank transparency is that the overnight interest rate is just not that important for most economic transactions. What matter are longer rates, as well as other prices that reflect expectations over relatively long horizons, such as exchange rates, stock prices, or even real estate prices. All of these are only loosely connected to the overnight rate. The one-year interest rate, for example, should depend on 365 consecutive overnight rates, yet the central bank determines directly only today's overnight rate; the other 364 are expectations of future rates. Influencing expectations, Blinder concluded, is the essence of monetary policy, and the relevant question is whether transparency aids in that task. 
Blinder noted further that central bank transparency relates not just to the central bank's forecasts - the focus of the authors' analysis-but also to the central bank's own future actions. He found it hard to see how the public's forecast of the Federal Reserve's behavior could improve on the Fed's own forecasts of that behavior. Hence he did not believe the authors' argument as it related to transparency about the central bank's intentions. Blinder concluded that reducing the information that the central bank provides about its own future actions would almost certainly result in efficiency losses. But he recognized that, in practice, it would be almost impossible for central banks to forecast their own behavior without revealing their underlying economic forecast; hence the issues raised by Morris and Shin arose indirectly.

Blinder also observed that private Wall Street forecasters are not the typical economic agents assumed in most economic models. Wall Street analysts pay a lot of attention to Federal Reserve forecasts, but most other economic agents do not. Therefore Blinder thought it unlikely that increased transparency would significantly reduce the flow of information about the economy coming from these agents: decisionmakers at Boeing, General Motors, and Wal-Mart are not likely to put less effort into forecasting their markets just because the Federal Reserve reveals more about its view of the economy. Finally, Blinder reminded the panel that, apart from considerations of policy effectiveness, there is an important social value to openness in a democracy. As a public body, the central bank should be accountable to the public, and transparency is an important element of accountability.

David Laibson suggested that central bankers like to be seen by the public as having substantial control over the economy. In reality, however, the future path of the economy is subject to much uncertainty, which the public fails to recognize. Therein, in Laibson's view, lies the principal benefit of central bank transparency: it requires explicit central bank forecasts of the economy. If central bankers focus on a single path, or if they place unrealistically narrow error bands on their estimates, the public will come to realize that they are being overconfident. In highly uncertain times, these error bands on central bank forecasts will have to be especially wide. Transparency will therefore result in the public having a more realistic assessment of future uncertainty, to which they can respond appropriately. Laibson drew parallels with the current debate between the Congressional Budget Office and the White House over the federal budget deficit. He believed that such debate is important and that a similarly open dialogue among central bankers could prove equally valuable. 
James Duesenberry agreed that the central bank's control over the economy was limited, and he suggested that the paper exaggerated the Federal Reserve's influence. The Federal Reserve controls monetary policy but has no control over many other factors - the federal budget, trade, private saving and investment decisions-that also matter to economic outcomes. Uncertainty about these factors and about the response of output, wages, and prices to changes in these factors not only makes forecasts uncertain, but also creates uncertainty about the effects of policy itself. Duesenberry mentioned two significant changes of the last few decades-a lesser role of unions and a greater impact of foreign competition in the inflation process - that have changed the response to whatever action the Federal Reserve might take.

Duesenberry emphasized that the Federal Reserve is faced with uncertainty about its forecasts and with an economy whose structure changes over time. Furthermore, the effects of its own policy instruments are uncertain and occur only with long lags. Duesenberry thought it entirely appropriate in these circumstances for the Federal Reserve to behave as it has most of the time under Chairman Alan Greenspan, moving policy in the direction it thinks appropriate, but only a little bit at a time. He recognized that certain exceptional circumstances would justify sudden moves, but he argued that, most of the time, gradualism combined with targets, which are partly inflation targets, partly employment targets, and partly other things, is the right way to go. But with this mode of conducting policy it was difficult to envisage the Federal Reserve coming out with a clear-cut announcement of what it is doing and why-the process is just too complicated.

Edmund Phelps found the authors' contrast of the views of Friedrich von Hayek with those of Oskar Lange somewhat misleading. Hayek argued that only a market economy could make effective use of the specialized knowledge held only at the industry level; Lange argued that socialism could work like a market economy by auctioning goods to generate prices, using the private information of socialist managers in the process. Both Lange and Hayek valued markets, although it is true that Lange did not address the issue of freedom for entrepreneurial initiative, which Hayek clearly had in mind.

The discussion then turned to the relationship between transparency and inflation targeting. Phelps was sympathetic to the authors' views and was surprised that Christopher Sims and Benjamin Friedman seemed so skeptical in their discussions of the paper. Phelps noted that, during the second 
half of the 1990s, he and some other observers had believed the economy was experiencing a structural change, which he regarded as a structural boom causing a temporary fall in the natural rate of unemployment. Reinforcing this belief was the fact that the inflation rate was tending downward. Phelps argued that this information value of the inflation rate would have been lost if the Federal Reserve had openly and credibly aimed at a fixed and explicit inflation rate target. Sims countered that the low inflation of the 1990s still would have taken place and still would have been informative had there been inflation targeting. The Federal Reserve would have had to undertake surprisingly easy monetary policy in order to reach its target, and that would have provided the same information. In fact, Sims thought, one could argue that monetary policy and the actual inflation process were not very different from what they would have been with inflation targeting. Duesenberry commented that the Federal Reserve needs to recognize that focusing only on inflation can have considerable cost, both social and political. Although in some circumstances these costs may be the price that has to be paid to end inflation, they should be taken into account in deciding policy.

Ellen Meade pointed out that the Federal Reserve has increased its transparency in many ways since the early 1990s, for example by announcing that it was targeting the federal funds rate and by releasing transcripts of Federal Open Market Committee meetings. The conclusions of the present paper were not inconsistent with these steps being in the right direction; the authors were simply arguing that, in the limit, such transparency could be counterproductive. She wished the authors had provided some empirical evidence about where that limit lies. Benjamin Friedman agreed and further argued that the Federal Reserve in recent years has been much more transparent than the Bank of England and many other inflationtargeting central banks. A central bank that targets inflation is not necessarily more transparent in conveying its views of the economy than one that does not. William Brainard concurred and remarked that there were a multitude of factors about which the central bank could be more or less transparent. Inflation targeting provides transparency about the central bank's objective function. Some have argued that this provides a major benefit by helping anchor the public's inflation expectations. But anchoring expectations about output may be at least as important, if firms' investment decisions depend more on their expectations about the need for additional capacity than on interest rates or inflation. 


\section{References}

Adam, Klaus. 2003. "Optimal Monetary Policy with Imperfect Common Knowledge." Working paper. Frankfurt University.

Allen, Franklin, Stephen Morris, and Hyun Song Shin. Forthcoming. "Beauty Contests and Iterated Expectations in Asset Markets." Review of Financial Studies.

Amato, Jeffery, and Hyun Song Shin. Forthcoming. "Imperfect Common Knowledge and the Information Value of Prices." Economic Theory.

Angeletos, George-Marios, and Alessandro Pavan. 2004. "Transparency of Information and Coordination in Economies with Investment Complementarities." American Economic Review 94, no. 2: 91-98.

2005. "Efficiency and Welfare in Economies with Incomplete Information." Working paper. Massachusetts Institute of Technology and Northwestern University (September).

Bacchetta, Philippe, and Eric van Wincoop. 2003. "Can Information Heterogeneity Explain the Exchange Rate Determination Puzzle?” Working Paper 03.02. Gersenzee, Switzerland: Studienzentrum Gerzensee (January).

2004. "Higher Order Expectations in Asset Pricing." Working Paper 04.03. Gersenzee, Switzerland: Studienzentrum Gerzensee (May).

Ball, Laurence, and Niamh Sheridan. 2003. "Does Inflation Targeting Matter?" In The Inflation-Targeting Debate, edited by Ben S. Bernanke and Michael Woodford. University of Chicago Press for the National Bureau of Economic Research.

Bank of England. 2005. Inflation Report. London (August) (www.bankofengland. co.uk/publications/inflationreport/2005.htm).

Bean, Charles. 2003. "Asset Prices, Financial Imbalances and Monetary Policy: Are Inflation Targets Enough?" Paper presented at the Reserve Bank of Australia annual conference, Sydney, August 18-19 (www.rba.gov.au/Publications AndResearch/Conferences/2003/Bean.pdf).

Bernanke, Ben S. 2004a. "Central Bank Talk and Monetary Policy.” Remarks at the Japan Society Corporate Luncheon, New York, October 7 (www.federalreserve.gov/boarddocs/speeches/2004/200410072/default.htm).

2004b. "The Logic of Monetary Policy." Remarks before the National Economists Club, December 2 (www.federalreserve.gov/boarddocs/ speeches/2004/20041202/default.htm).

Bernanke, Ben S., and Frederic S. Mishkin. 1997. "Inflation Targeting: A New Framework for Monetary Policy?" Journal of Economic Perspectives 11, no. 2: 97-116.

Bernanke, Ben S., and others. 2001. Inflation Targeting: Lessons from the International Experience. Princeton University Press.

Blanchard, Olivier, and John Simon. 2001. "The Long and Large Decline in U.S. Output Volatility." BPEA, no. 1: 135-64. 
Blinder, Alan S. 1998. Central Banking in Theory and Practice. MIT Press.

Brayton, Flint, John M. Roberts, and John C. Williams. 1999. "What's Happened to the Phillips Curve?" Finance and Economics Discussion Series 1999-49. Federal Reserve Board (www.federalreserve.gov/pubs/feds/1999/199949/199949 pap.pdf).

Campbell, Sean D. 2004. "Macroeconomic Volatility, Predictability and Uncertainty in the Great Moderation: Evidence from the Survey of Professional Forecasters." Finance and Economics Discussion Series 2004-52. Federal Reserve Board (www.federalreserve.gov/pubs/feds/2004/200452/200452pap.pdf).

Chen, Qi, Itay Goldstein, and Wei Jiang. 2005. "Price Informativeness and Investment Sensitivity to Stock Price." Working paper. Fuqua School of Business and Columbia Business School (February).

Committee on National Statistics. 1985. Natural Gas Data Needs in a Changing Regulatory Environment. National Research Council Panel on Statistics of Natural Gas (sims.princeton.edu/yftp/NatGas/CHAPIII.pdf).

Cornell, Bradford. 1983. "The Money Supply Announcements Puzzle: Review and Interpretation." American Economic Review 73, no. 4: 644-57.

Fisher, Irving. 1930. The Theory of Interest. Macmillan.

Fleming, Michael J., and Eli M. Remolona. 1999. "Price Formation and Liquidity in the U.S. Treasury Market: The Response to Public Information." Journal of Finance 54, no. 5: 1901-15.

Galí, Jordi, and Mark Gertler. 1999. "Inflation Dynamics: A Structural Econometric Analysis." Journal of Monetary Economics 44, no. 2: 195-222.

Geraats, Petra M. 2002. "Central Bank Transparency." The Economic Journal 112, no. 483: 532-65.

Goodhart, C. A. E. 2004. "The Interaction between the Bank of England's Forecasts and Policy, and the Outturn." Working paper. Financial Markets Group, London School of Economics (May).

Grossman, Sanford J. 1976. "On the Efficiency of Competitive Stock Markets Where Traders Have Diverse Information." Journal of Finance 31, no. 2: 573-85.

Gurkaynak, Refet, Andrew Levin, and Eric Swanson. 2005. "Inflation Targeting and the Anchoring of Long-Run Inflation Expectations: International Evidence from Daily Bond Yield Data." Paper prepared for the Riksbank Workshop on Inflation Targeting, Stockholm, June.

Gurkaynak, Refet, Brian Sack, and Eric Swanson. 2005. "The Sensitivity of LongTerm Interest Rates to Economic News: Evidence and Implications for Macroeconomic Models." American Economic Review 95, no. 1: 425-36.

Hayek, Friedrich A. 1945. "The Use of Knowledge in Society." American Economic Review 35, no. 4: 519-30.

Hellwig, Christian. 2002. "Public Announcements, Adjustment Delays and the Business Cycle." Working paper. University of California, Los Angeles (November). 
2004. "Heterogeneous Information and the Benefits of Transparency." Working paper. University of California, Los Angeles (December).

Hirshleifer, Jack. 1971. "The Private and Social Value of Information and the Reward to Inventive Activity." American Economic Review 61, no. 4: 561-74.

Kasa, Kenneth. 2000. "Forecasting the Forecasts of Others in the Frequency Domain." Review of Economic Dynamics 3, no. 4: 726-56.

Keynes, John Maynard. 1936. The General Theory of Employment, Interest, and Money. London: MacMillan.

Kim, Chang-Jin, and Charles R. Nelson. 1999. "Has the U.S. Economy Become More Stable? A Bayesian Approach Based on a Markov-Switching Model of the Business Cycle." Review of Economics and Statistics 81, no. 4: 608-16.

Kohn, Donald L. 2005. "Central Bank Communication.” Remarks at the annual meeting of the American Economic Association, Philadelphia, January 9 (www.federalreserve.gov/boarddocs/speeches/2005/20050109/default.htm).

Kuttner, Kenneth N. 2004. "The Role of Policy Rules in Inflation Targeting.” Federal Reserve Bank of St. Louis Review, pp. 89-112 (July).

Lange, O. 1936. "On the Economic Theory of Socialism: Part One." Review of Economic Studies 4, no. 1: 53-71.

1937. "On the Economic Theory of Socialism: Part Two." Review of Economic Studies 4, no. 2: 123-42.

Leiderman, Leonardo, and Lars E. O. Svensson. 1995. Inflation Targets. London: Centre for Economic Policy Research.

Levin, Andrew T., Fabio Massimo Natalucci, and Jeremy Piger. 2004. "Explicit Inflation Objectives and Macroeconomic Outcomes.” Working Paper 383. Frankfurt: European Central Bank (August).

Lucas, Robert E. 1972. "Expectations and the Neutrality of Money." Journal of Economic Theory 4, no. 2: 103-24.

1973. "Some International Evidence on Output-Inflation Tradeoffs." American Economic Review 63, no. 3: 326-34.

Mackowiak, Bartosz, and Mirko Wiederholt. 2005. “Optimal Sticky Prices under Rational Inattention.” Working paper. Berlin: Humboldt University (July).

Mankiw, N. Gregory, Ricardo Reis, and Justin Wolfers. 2004. "Disagreement about Inflation Expectations.” In NBER Macroeconomics Annual 2003, edited by Mark Gertler and Kenneth Rogoff. MIT Press.

McConnell, Margaret M., and Gabriel Perez-Quiros. 2000. "Output Fluctuations in the United States: What Has Changed Since the Early 1980s?" American Economic Review 90, no. 5: 1464-76.

Meade, Ellen E., and David Stasavage. 2005. "Publicity of Debate and the Incentive to Dissent: Evidence from the US Federal Reserve." Working paper. American University and London School of Economics (June).

Morris, Stephen, and Hyun Song Shin. 2002. "Social Value of Public Information." American Economic Review 92, no. 5: 1521-34. 
Morris, Stephen, Hyun Song Shin, and Hui Tong. Forthcoming. "Response to 'Social Value of Public Information: Morris and Shin (2002) is Actually Pro Transparency, Not Con.' "American Economic Review.

Pearlman, Joseph G., and Thomas J. Sargent. 2005. "Knowing the Forecasts of Others." Review of Economic Dynamics 8, no. 2: 480-97.

Phelps, Edmund S. 1970. "Introduction." In Microeconomic Foundations of Employment and Inflation Theory, edited by Edmund S. Phelps and others. Norton.

1983. "The Trouble with Rational Expectations and the Problem of Inflation Stabilization.” In Individual Forecasting and Aggregate Outcomes, edited by Roman Frydman and Edmund S. Phelps. Cambridge University Press.

Polk, Christopher, and Paola Sapienza. 2004. "The Real Effects of Investor Sentiment." Working Paper 10563. Cambridge, Mass.: National Bureau of Economic Research.

Radner, Roy. 1979. "Rational Expectations Equilibrium: Generic Existence and the Information Revealed by Prices." Econometrica 47, no. 3: 655-78.

Rogoff, Kenneth. 2003. "Globalization and Global Disinflation." Paper presented at the annual Federal Reserve Bank of Kansas City Symposium, Jackson Hole, Wyoming, August 28-30.

Roley, V. Vance. 1983. "The Response of Short-Term Interest Rates to Weekly Money Announcements." Journal of Money, Credit and Banking 15, no. 3: 344-54.

Roley, V. Vance, and Carl E. Walsh. 1985. "Monetary Policy Regimes, Expected Inflation, and the Response of Interest Rates to Money Announcements." Quarterly Journal of Economics 100, Supplement: 1011-39.

Romer, Christina D., and David H. Romer. 2000. "Federal Reserve Information and the Behavior of Interest Rates." American Economic Review 90, no. 3: 429-57.

Sargent, Thomas J. 1991. "Equilibrium with Signal Extraction from Endogenous Variables." Journal of Economic Dynamics and Control 15, no. 2: 245-73.

Schuh, Scott. 2001. "An Evaluation of Recent Macroeconomic Forecast Errors." New England Economic Review, January-February, pp. 35-56. Federal Reserve Bank of Boston.

Sims, Christopher A. 2002. "The Role of Models and Probabilities in the Monetary Policy Process.” BPEA, no. 2: 1-40.

2003. "Implications of Rational Inattention." Journal of Monetary Economics 50, no. 3: 665-90.

Svensson, Lars E. O. 1999. "Inflation Targeting as a Monetary Policy Rule.” Journal of Monetary Economics 43, no. 3: 607-54.

2004. "Challenges for Monetary Policy." Paper prepared for the Bellagio Group Meeting at the National Bank of Belgium, Brussels, January 26-27 (www.princeton.edu/ svensson/papers/401bru.pdf). 
Forthcoming. "Social Value of Public Information: Morris and Shin (2002) is Actually Pro Transparency, Not Con." American Economic Review.

Svensson, Lars E. O., and Michael Woodford. 2005. "Implementing Optimal Policy through Inflation-Forecast Targeting." In The Inflation-Targeting Debate, edited by Ben S. Bernanke and Michael Woodford. University of Chicago Press.

Townsend, Robert M. 1983. "Forecasting the Forecasts of Others." Journal of Political Economy 91, no. 4: 546-88.

Tulip, Peter. 2005. "Has Output Become More Predictable? Changes in Greenbook Forecast Accuracy." Finance and Economics Discussion Series 2005-31. Federal Reserve Board.

Ui, Takashi. 2003. "A Note on the Lucas Model: Iterated Expectations and the Neutrality of Money." Working paper. Yokohama National University (November).

Woodford, Michael. 2003a. "Imperfect Common Knowledge and the Effects of Monetary Policy." In Knowledge, Information and Expectations in Modern Macroeconomics: In Honor of Edmund S. Phelps, edited by Philippe Aghion, Roman Frydman, Joseph Stiglitz, and Michael Woodford. Princeton University Press.

2003b. Interest and Prices: Foundations of a Theory of Monetary Policy. Princeton University Press.

. 2005. "Central-Bank Communication and Policy Effectiveness." Paper presented at the Federal Reserve Bank of Kansas City Symposium, Jackson Hole, Wyoming, August 25-27. 